Article

\title{
Development and Verification of an Aero-Hydro-Servo-Elastic Coupled Model of Dynamics for FOWT, Based on the MoWiT Library
}

\author{
Mareike Leimeister ${ }^{1,2, *}$, Athanasios Kolios ${ }^{1}$ and Maurizio Collu ${ }^{1}$ D \\ 1 Naval Architecture, Ocean and Marine Engineering, University of Strathclyde, Glasgow G4 0LZ, UK; \\ athanasios.kolios@strath.ac.uk (A.K.); maurizio.collu@strath.ac.uk (M.C.) \\ 2 Fraunhofer IWES, Fraunhofer Institute for Wind Energy Systems, Am Luneort 100, \\ 27572 Bremerhaven, Germany \\ * Correspondence: mareike.leimeister@iwes.fraunhofer.de
}

Received: 21 March 2020; Accepted: 9 April 2020; Published: 16 April 2020

\begin{abstract}
The complexity of floating offshore wind turbine (FOWT) systems, with their coupled motions, aero-hydro-servo-elastic dynamics, as well as non-linear system behavior and components, makes modeling and simulation indispensable. To ensure the correct implementation of the multi-physics, the engineering models and codes have to be verified and, subsequently, validated for proving the realistic representation of the real system behavior. Within the IEA (International Energy Agency) Wind Task 23 Subtask 2 offshore code-to-code comparisons have been performed. Based on these studies, using the OC3 phase IV spar-buoy FOWT system, the Modelica for Wind Turbines (MoWiT) library, developed at Fraunhofer IWES, is verified. MoWiT is capable of fully-coupled aero-hydro-servo-elastic simulations of wind turbine systems, onshore, offshore bottom-fixed, or even offshore floating. The hierarchical programing and multibody approach in the object-oriented and equation-based modeling language Modelica have the advantage (over some other simulation tools) of component-based modeling and, hence, easily modifying the implemented system model. The code-to-code comparisons with the results from the OC 3 studies show, apart from expected differences due to required assumptions in consequence of missing data and incomplete information, good agreement and, consequently, substantiate the capability of MoWiT for fully-coupled aero-hydro-servo-elastic simulations of FOWT systems.
\end{abstract}

Keywords: OC3 phase IV; Modelica; MoWiT; code-to-code comparison; floating offshore wind turbines; spar-buoy

\section{Introduction and Outline}

Offshore wind energy is becoming more and more interesting for the renewable energy industry. Depending on the location, water depth, and seabed conditions, different offshore wind turbine systems are required. Bottom-fixed solutions, such as monopiles, jackets, tripods, gravity-based structures, or suction buckets are limited to shallow and intermediate water depths. For deeper water sites, floating platforms, such as spar-buoys, semi-submersibles, or tension leg platforms, are required to support offshore wind turbines. Especially, spar-type floating support structures for offshore wind turbines are judged as being highly prospective for utilization in large commercial wind farms [1,2].

In comparison to onshore systems, offshore wind turbines have to deal with hydrodynamic loads in addition to wind loads. For floating offshore wind turbines (FOWTs) the system complexity increases even more. Apart from the environmental loads from wind, waves, and currents, the motion of the floating system leads to relative velocities, which have to be accounted for in the aerodynamic 
and hydrodynamic load calculations. Variable buoyancy loads are as well a consequence of the free motion of the system. Nevertheless, to keep the floater within a specific site, FOWTs have an additional component-the mooring system. This consists mostly of catenary mooring lines, or tendons in case of a tension leg floating platform, and anchors to fix the lines to the seabed. Thus, a FOWT system implies motion couplings, several different loading components, as well as non-linearities [3-6].

For this reason, modeling and simulation techniques are crucial for the assessment of FOWT system designs. However, it has to be ensured that the physical equations are correctly implemented in the code and the system behavior is realistically represented by the model. This is to be proved through verification and validation. Before validating the FOWT model, which in addition requires real measurements or test data, the code needs to be verified. Within the IEA (International Energy Agency) Wind Task 23 Subtask 2, the Offshore Code Comparison Collaboration (OC3) was developed to verify offshore wind turbine codes based on code-to-code comparison works [7].

The participants of OC3 phase IV, which is on verifying a model of a floating spar-buoy offshore wind turbine system (described in detail in Section 2.1) [8], used various aero-hydro-servo-elastic modeling approaches as presented in Figure 1. Very common and widely used tools are among others Bladed, HAWC2, and FAST. The wind turbine design software Bladed is a commercial software by DNV GL (Det Norske Veritas and Germanischer Lloyd), which is highly established and continuously enhanced in each newer version, is applied for system simulations, design, and certification, and has further advanced modules for specific applications such as advanced hydrodynamic calculations $[9,10]$. Another commercial aero-elastic code for wind turbine system simulation and response calculation is HAWC2 (Horizontal Axis Wind turbine simulation Code 2nd generation) developed at DTU (Technical University of Denmark) Risø Campus, which no longer only is used for aero-elastic simulations but also can represent floating systems [11]. As well commercial, but right now also transferred to open-source development, is FAST (Fatigue, Aerodynamics, Structures, and Turbulence)-a simulation tool developed and used at NREL (National Renewable Energy Laboratory) for coupled analyses of horizontal-axis wind turbines, which can be combined with several other programs and packages for further advanced and detailed analyses, such as structural finite element analysis [12]. Further software and modeling tools are for example ADAMS (Automatic Dynamic Analysis of Mechanical Systems) by MSC Software for simulating multibody dynamics of mechanical systems, which can as well be applied to FLOWTs [13]; SIMO (Simulation of Marine Operations) by the Norwegian Marine Technology Research Institute (MARINTEK) for floating systems (originally mainly vessels) simulation, which can be advanced by means of the code RIFLEX for non-linear mooring line dynamics, coupled with HAWC2, and also be used for wind turbine systems by incorporating an external aerodynamic module [14]; 3Dfloat developed at the Institute for Energy Technology at the (then called) University of Life Sciences (IFE-UMB) for fully-coupled simulation and advanced analyses of offshore structures, such as FOWTs [15]; or SESAM software with the DeepC module by DNV GL for simulation and (un-)coupled analyses of floating structures and station-keeping systems, which however require a separate approach for integrating aerodynamics for a full offshore wind turbine system [5]. More detailed reviews of the utilized modeling tools are provided in Reference $[16,17]$ and the physics and theories implemented in the tools-all abbreviations mentioned under aerodynamics, hydrodynamics, control system, and structural dynamics in Figure 1-are described in more detail in Sections 3.1 and 4.2.

The results from these offshore code-to-code comparisons are used to verify a model of the above mentioned and in Section 2.1 particularized floating spar-buoy wind turbine system from phase IV of OC3 [8], which is implemented in MoWiT (Modelica for Wind Turbines) (formerly OneWind) , a library developed at Fraunhofer IWES (Institute for Wind Energy Systems), based on the object-oriented and equation-based modeling language Modelica (https:/ / www.modelica.org/ accessed: 15 January 2019). One advantage of using Modelica for modeling wind turbine systems is the hierarchical programing, by which means the complex system can be subdivided into single components. Thus, this component-based MoWiT library allows for modifications and replacements of individual component 
models, so that modeling and simulation of different system designs and boundary conditions can be realized. Furthermore, due to the possibility to couple MoWiT models to Python scripts, many more doors are being open for automated simulations, such as for design load case calculations, post-processing and analyses of simulation results, as well as other extensive tasks and applications, such as system optimization [18-21]. However, all these benefits would be as good as useless if the model and code is not yet verified.

\begin{tabular}{|c|c|c|c|c|c|c|c|}
\hline Bladed & HAWC2 & FAST & ADAMS & SESAM/DeepC & Simo & 3Dfloat & MoWiT \\
\hline \multicolumn{8}{|c|}{ Code Developer } \\
\hline GH & Risø-DTU & NREL & $\begin{array}{l}\text { MSC + NREL } \\
+ \text { LUH }\end{array}$ & DNV & MARINTEK & IFE-UMB & IWES \\
\hline \multicolumn{8}{|c|}{ OC3 Participant } \\
\hline \multirow{2}{*}{ GH } & \multirow{2}{*}{ Risø-DTU } & NREL & \multirow{2}{*}{$\begin{array}{l}\text { NREL } \\
\text { LUH }\end{array}$} & Acciona & \multirow{2}{*}{ MARINTEK } & \multirow{2}{*}{ IFE-UMB } & \multirow{2}{*}{ IWES } \\
\hline & & POSTECH & & NTNU & & & \\
\hline \multicolumn{8}{|c|}{ Aerodynamics } \\
\hline \multicolumn{4}{|c|}{$(B E M / G D W)+D S$} & none & BEM & (BEM / GDW) & $\begin{array}{l}\text { (BEM / GDW) } \\
+ \text { + DS }\end{array}$ \\
\hline \multicolumn{8}{|c|}{ Hydrodynamics } \\
\hline $\begin{array}{c}\text { (Airy+ / Stream) } \\
+ \text { ME }\end{array}$ & Airy + ME & \multicolumn{3}{|c|}{$($ Airy + + ME) / (Airy + ME + PF) } & $\begin{array}{l}\text { Airy + ME + } \\
\text { PF }\end{array}$ & Airy + ME & $\begin{array}{l}\text { Airy + WS + } \\
\text { (ME / MCF) }\end{array}$ \\
\hline \multicolumn{8}{|c|}{ Control System (Servo) } \\
\hline DLL & DLL / & / SM & DLL / UD & none & DLL & UD & DLL / UD \\
\hline \multicolumn{8}{|c|}{ Structural Dynamics (Elastic) } \\
\hline \multicolumn{8}{|c|}{ Turbine } \\
\hline FEMP & $\mathrm{MBD} / \mathrm{FEM}$ & $\begin{array}{c}\text { FEMP + } \\
\text { (Modal / } \\
\text { MBD) }\end{array}$ & \multicolumn{2}{|c|}{ MBD } & MBD & FEM & $\begin{array}{l}\text { (FEM / Modal) } \\
\quad+\text { MBD }\end{array}$ \\
\hline \multicolumn{8}{|c|}{ Mooring } \\
\hline \multicolumn{2}{|c|}{ UDFD } & QSCE & QSCE / UDFD & QSCE / FEM & QSCE / MBD & FEM / UDFD & MBD \\
\hline
\end{tabular}

Figure 1. Aero-hydro-servo-elastic modeling approaches of the OC3 phase IV participants [7] and IWES.

Thus, the aim of this paper is to develop a fully-coupled FOWT system model based on the MoWiT library. This implemented model of dynamics shall be capable of aero-hydro-servo-elastic time-domain simulations and be highly flexible with respect to the considered ((floating) offshore) wind turbine system and environmental conditions. By means of code-to-code comparisons, utilizing the OC3 phase IV floating spar-buoy system and corresponding results from previous research work, the developed fully-coupled FOWT system model shall be verified.

In this paper, first, the considered spar-buoy floating offshore wind turbine system from phase IV of OC3 is introduced in Section 2. Based on the system definition, the FOWT is implemented in Modelica using the MoWiT library (Section 3). Afterwards, the main task of verifying this model is performed based on code-to-code comparison works and results are presented in Section 4. More detailed discussion and analyses of the results follow in Section 5. Finally, some conclusions, including a short summary and outlook, are given in Section 6.

\section{OC3 Phase IV Floating Spar-Buoy Wind Turbine System}

In phase IV of OC3 a spar-buoy FOWT system was used [8], as shown in Figure 2. The floater is based on the Hywind spar-buoy and modified to support the NREL 5 MW reference wind turbine [22]. The entire FOWT system is specified for a site with $320 \mathrm{~m}$ water depth and a water density of $1025 \mathrm{~kg} / \mathrm{m}^{3}$. In the following, the main parameters of this FOWT system are introduced.

\subsection{The OC3 Phase IV Floater}

The platform of the OC3 FOWT system is a spar-buoy, which is based on the Hywind floater. The main structural parameters are provided in the definition of the FOWT system [8]. Comparison of the specified values shows that the dimensions-apart from the improved and reduced draft of the real systems-lie in between the dimensions of the Hywind Demo for a $2.3 \mathrm{MW}$ wind turbine and the Hywind Scotland floater supporting a 6.0 MW wind turbine (https: / / www.equinor.com/en/what- 
we-do/floating-wind/how-hywind-works.html accessed: 3 April 2020). The geometrical parameters are presented in Table 1 and indicated, using green color, in a schematic drawing of the OC 3 spar-buoy (Figure 3). Distances to the top and bottom ends of the floating structure are measured with respect to the still water level (SWL). The remaining parameters, written in red in Figure 3, are as well basic system parameters, but not explicitly defined. This issue is taken up again in Section 3 when it comes to the modeling of the FOWT system in Modelica.

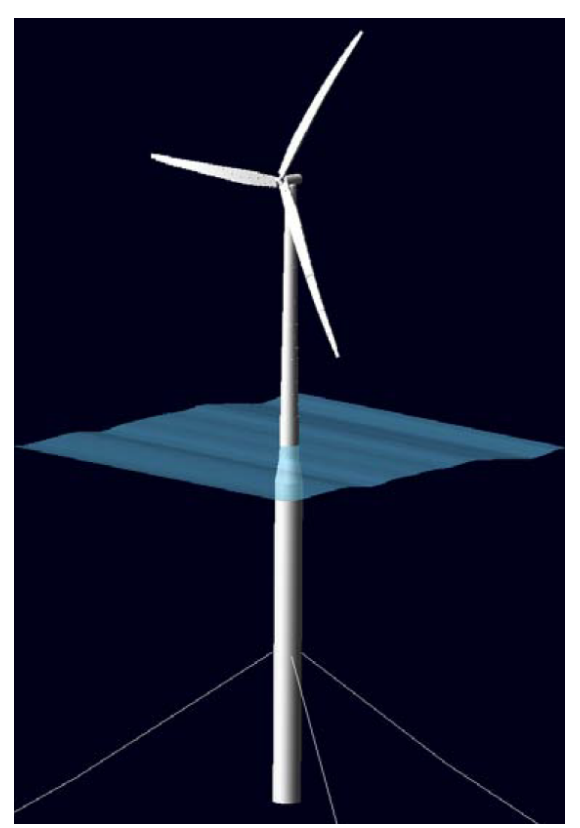

Figure 2. Model of the OC3 spar-buoy floating offshore wind turbine (FOWT) system; Reprint with permission [8]; 2010, NREL.

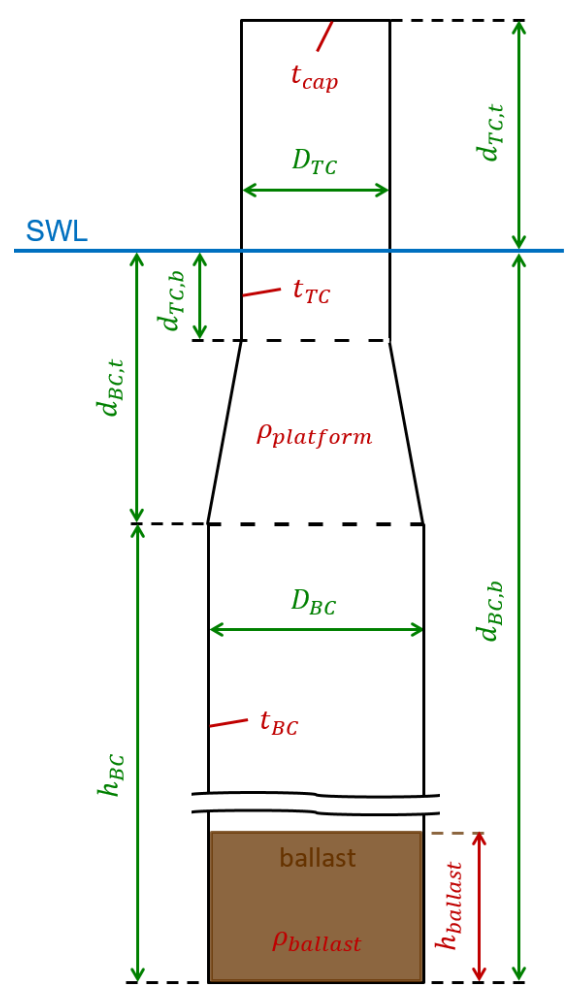

Figure 3. Schematic of the OC3 spar-buoy. 
Table 1. Geometrical parameters of the OC3 spar-buoy [8].

\begin{tabular}{lcc}
\hline Parameter & Symbol & Value \\
\hline Top cylinder diameter & $D_{\mathrm{TC}}$ & $6.5 \mathrm{~m}$ \\
Bottom cylinder diameter & $D_{\mathrm{BC}}$ & $9.4 \mathrm{~m}$ \\
Distance to top of top cylinder & $d_{\mathrm{TC}, \mathrm{t}}$ & $10.0 \mathrm{~m}$ \\
Distance to base of top cylinder & $d_{\mathrm{TC}, \mathrm{b}}$ & $4.0 \mathrm{~m}$ \\
Distance to top of bottom cylinder & $d_{\mathrm{BC}, \mathrm{t}}$ & $12.0 \mathrm{~m}$ \\
Distance to base of bottom cylinder & $d_{\mathrm{BC}, \mathrm{b}}$ & $120.0 \mathrm{~m}$ \\
Height of bottom cylinder & $h_{\mathrm{BC}}$ & $108.0 \mathrm{~m}$ \\
\hline
\end{tabular}

In addition to the geometrical spar-buoy parameters, given in Table 1, some mass-related properties are provided in Reference [8] and presented in Table 2. Furthermore, for the hydrodynamic characteristics of the floating platform, the added-mass coefficient is given as 0.969954 [8], which is close to the typical value of 1 for circular cylinders [23], while the viscous-drag coefficient amounts to 0.6 [8] and corresponds to the common value at high Reynolds number, which is already prevailing at low flow velocities for a large diameter structure as this spar-buoy $[23,24]$. The hydrostatic buoyancy force, determined from the displaced water volume, is stated as $80,708,100 \mathrm{~N}$ [8]. To get closer to the Hywind floater characteristics, additional linear damping in surge and sway of $100 \times 10^{3} \mathrm{Ns} / \mathrm{m}$ each, in heave of $130 \times 10^{3} \mathrm{Ns} / \mathrm{m}$, and in yaw of $13 \times 10^{6} \mathrm{Nms} / \mathrm{rad}$ are applied per definition in Reference [8].

Table 2. Mass-related properties of the OC3 spar-buoy, prescribed values in comparison with the model results.

\begin{tabular}{lccc}
\hline Parameter & $\begin{array}{c}\text { Value per } \\
\text { Definition [8] }\end{array}$ & $\begin{array}{c}\text { Value in } \\
\text { MoWiT Model }\end{array}$ & Deviation \\
\hline Platform mass (including ballast) & $7466.3 \mathrm{t}$ & $7466.3 \mathrm{t}$ & $0.0 \%$ \\
Center of mass (below SWL along central axis) & $89.9155 \mathrm{~m}$ & $89.9136 \mathrm{~m}$ & $-2.1 \times 10^{-3} \%$ \\
Platform roll inertia (about center of mass) & $4229.23 \times 10^{6} \mathrm{kgm}^{2}$ & $4229.23 \times 10^{6} \mathrm{kgm}^{2}$ & $0.0 \%$ \\
Platform pitch inertia (about center of mass) & $4229.23 \times 10^{6} \mathrm{kgm}^{2}$ & $4229.23 \times 10^{6} \mathrm{kgm}^{2}$ & $0.0 \%$ \\
Platform yaw inertia (about central axis) & $164.23 \times 10^{6} \mathrm{kgm}^{2}$ & $92.67 \times 10^{6} \mathrm{kgm}^{2}$ & $-43.6 \%$ \\
\hline
\end{tabular}

The floating spar-buoy is moored with three catenary mooring lines at equally spaced fairlead positions $70.0 \mathrm{~m}$ below SWL and $5.2 \mathrm{~m}$ from the bottom cylinder centerline. The footprint of the anchors at the seabed amounts to $1707.74 \mathrm{~m}$ in diameter. Each of the mooring lines is $902.2 \mathrm{~m}$ long (unstretched), has a diameter of $0.09 \mathrm{~m}$, a mass density of $77.7066 \mathrm{~kg} / \mathrm{m}$, a length-related weight in water of $698.094 \mathrm{~N} / \mathrm{m}$, and an extensional stiffness of $384.243 \times 10^{3} \mathrm{~N}$. As this mooring system is a simplified version of the station-keeping system used for the Hywind floater, in which a delta connection is realized, an additional yaw spring stiffness of $98.34 \times 10^{6} \mathrm{Nm} / \mathrm{rad}$ has to be considered to correct for this [8].

\subsection{The OC3 Phase IV Wind Turbine}

On top of the OC3 spar-buoy, described in Section 2.1, the NREL 5 MW reference wind turbine [22], adjusted for the floating system, is placed. While the rotor-nacelle assembly (RNA), as well as the blade (aerodynamic) properties remain unchanged as defined for the NREL 5 MW turbine in Reference [22], a modified tower [8] was used for the OC3 spar-buoy floating wind turbine system to fit the platform top cylinder diameter and to maintain the hub height. Furthermore, the wind turbine control system parameters were retuned in phase IV of OC3, to avoid negative damping effects due to the floating system. The specified wind turbine properties for the OC3 floating system are summarized in Table 3. The resulting mass-related characteristics of the OC3 wind turbine (including the tower) are as presented in Table 4. 
Table 3. Properties of the wind turbine for the OC3 floating system.

\begin{tabular}{lc}
\hline Parameter & Value per Definition [8,22] \\
\hline Tower top diameter & $3.87 \mathrm{~m}$ \\
Tower top wall thickness & $0.019 \mathrm{~m}$ \\
Tower base diameter & $6.5 \mathrm{~m}$ \\
Tower base wall thickness & $0.027 \mathrm{~m}$ \\
Hub height & $90.0 \mathrm{~m}$ \\
Elevation of tower top & $87.6 \mathrm{~m}$ \\
Elevation of tower base & $10.0 \mathrm{~m}$ \\
Material density & $8500 \mathrm{~kg} / \mathrm{m}^{3}$ \\
Proportional gain at minimum blade-pitch setting & $0.006275604 \mathrm{~s}$ \\
Integral gain at minimum blade-pitch setting & 0.0008965149 \\
\hline
\end{tabular}

Table 4. Mass-related properties of the OC3 turbine, prescribed values in comparison with the model results.

\begin{tabular}{lccc}
\hline Parameter & Value per Definition [8] & Value in MoWiT Model & Deviation \\
\hline RNA mass & $350.0 \mathrm{t}$ & $350.0 \mathrm{t}$ & $0.0 \%$ \\
Tower mass & $249.7 \mathrm{t}$ & $249.6 \mathrm{t}$ & $-4.4 \times 10^{-2} \%$ \\
$\begin{array}{l}\text { Center of tower mass } \\
\text { (above SWL along central axis) }\end{array}$ & $43.4 \mathrm{~m}$ & $43.4 \mathrm{~m}$ & $0.0 \%$ \\
\hline
\end{tabular}

\section{Modeling of the OC3 FOWT in MoWiT}

Modeling of a FOWT system can be done by means of various software architectures, which are based on different simulation codes with varying capabilities for aero-hydro-servo-elastic calculations, as pointed out in References $[16,17]$. Within the OC3 project, the floating spar-buoy wind turbine system from phase IV, as described in Section 2, was modeled by the project participants in different codes and tools for wind turbine system simulation, as introduced in Section 1, to be compared and verified within the study [7]. For the same purpose of code verification and to add one more result to the cross-code comparison, the OC3 FOWT is implemented in the modeling language Modelica, using the MoWiT library for fully-coupled aero-hydro-servo-elastic dynamic simulation of wind turbine systems, developed at Fraunhofer IWES [25-27]. In the following, first (Section 3.1), this library and the modeling environment is introduced briefly to point out the advantages and capabilities of this tool. Afterwards (Section 3.2), the methodology of implementing the OC3 FOWT system is outlined, demonstrating as well difficulties which arose and assumptions that had to be made.

\subsection{The MoWiT Library}

The MoWiT library, which is developed at Fraunhofer IWES and is available free of charge for academic use, allows modeling of state-of-the-art onshore or offshore wind turbine systems to be simulated in Dymola (http://www.dymola.com/ accessed: 15 January 2019), the Dynamic modeling laboratory by Dessault Systèmes [28,29], for load calculations and further analyses. The component-based library is based on the object-oriented and equation-based open-source modeling language Modelica. The hierarchical structure of programing in Modelica, as well as the multibody approach adopted in Modelica, benefit the modeling of such a complex system as a wind turbine. Hence, the wind turbine system is broken down into single components (main and subcomponents), as shown in Figure 4, which are modeled separately and interconnected to represent correctly couplings and interactions between them. This structure also allows fast and easy exchange of single components to model different wind turbine technologies, turbine or support structure designs, control strategies, or site and environmental conditions. Furthermore, as MoWiT is under development by Fraunhofer IWES, code modifications, optimizations, and enhancements are always possible [19,25-27]. 


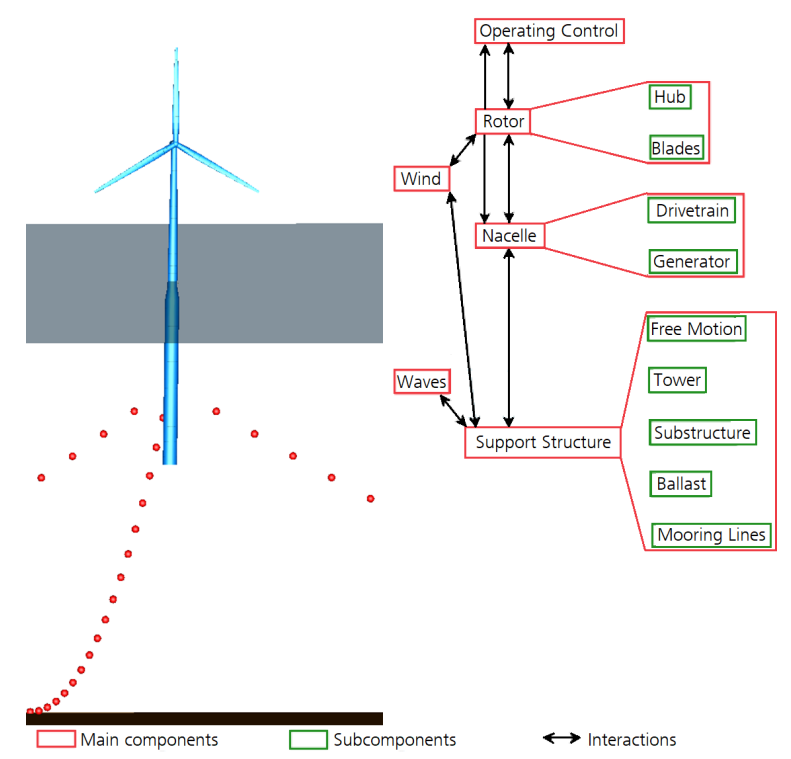

Figure 4. Hierarchical modeling structure of a FOWT system in Modelica for Wind Turbines (MoWiT), adapted by the author from Reference [25]; Reprint with permission [25]; 2017, Linköping University Electronic Press.

As presented in Figure 4, a FOWT, such as the OC3 spar-buoy system shown as well in Figure 5, consists of six main components, of which two are for the environmental parameters. Within these main components there are several subcomponents and options to be modeled. Hence, apart from the hub, a specified number of blades (for common wind turbines mostly three or two), represented as either rigid or flexible structures, make up the wind turbine rotor. This is, among others, connected to the nacelle with the structural models of drivetrain (rigid or flexible in one torsional degree of freedom) and generator (fixed or variable speed). The nacelle as well contains the yaw controller; however, the remaining control systems for pitch and torque control, following PI-algorithms or an external dynamic link library (DLL) for running various operating phases, are incorporated in the operating control. The whole representation of the floating structure-including the tower, potential ballast, and the station-keeping system-is done in the support structure model, comprising as well the determination of all (aerodynamic, hydrostatic, and hydrodynamic) loads and motions. With respect to the aerodynamics, MoWiT can base the calculations on the blade-element momentum (BEM) theory [30-33] or the generalized dynamic wake (GDW) model $[34,35]$ and incorporate corrections for dynamic wake and dynamic stall (DS); regarding the hydrodynamics, the library is capable of linear Airy [36] or non-linear Stokes wave theory [24,37], Wheeler stretching (WS) or delta stretching [38], Morison equation (ME) [39], and MacCamy-Fuchs (MCF) approach [40]. For the structural dynamics, the finite-element method (FEM), based on Euler-Bernoulli or Timoshenko beam theory, or modal reduction can be used for the floater and turbine representation, while the mooring lines are modeled through a mass-spring-damping (MSD) system, which considers, apart from the dynamic inertial motion of the mooring system, hydrodynamic and internal damping, elastic deformation, as well as soil contact, and uses the catenary equation for determining the initial shape and position of the mooring line elements. Finally, the two environmental models for wind and waves, including also currents, allow the realization of various steady or turbulent, regular or irregular, aligned or misaligned, and normal or extreme environmental conditions and sea states [25-27]. 


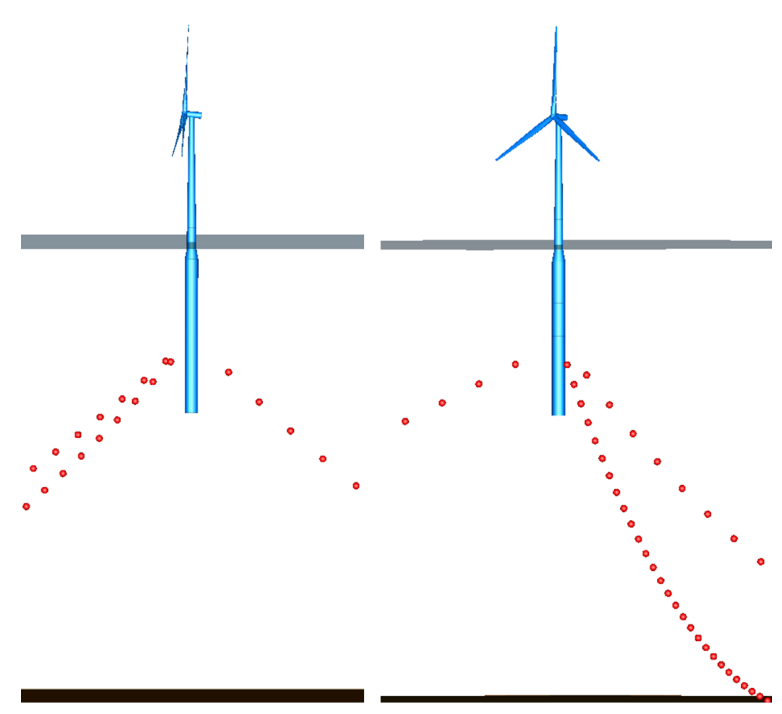

Figure 5. OC3 spar-buoy FOWT system modeled in MoWiT and visualized in Dymola; Reprint with permission [25]; 2017, Linköping University Electronic Press.

An overview of the structure of the MoWiT model is presented in Figure 6. It shows the required inputs for the wind turbine system and the environment and points out the approaches for the fully-coupled aero-hydro-servo-elastic dynamic calculations, based on which the final system responses are determined and obtained as outputs.

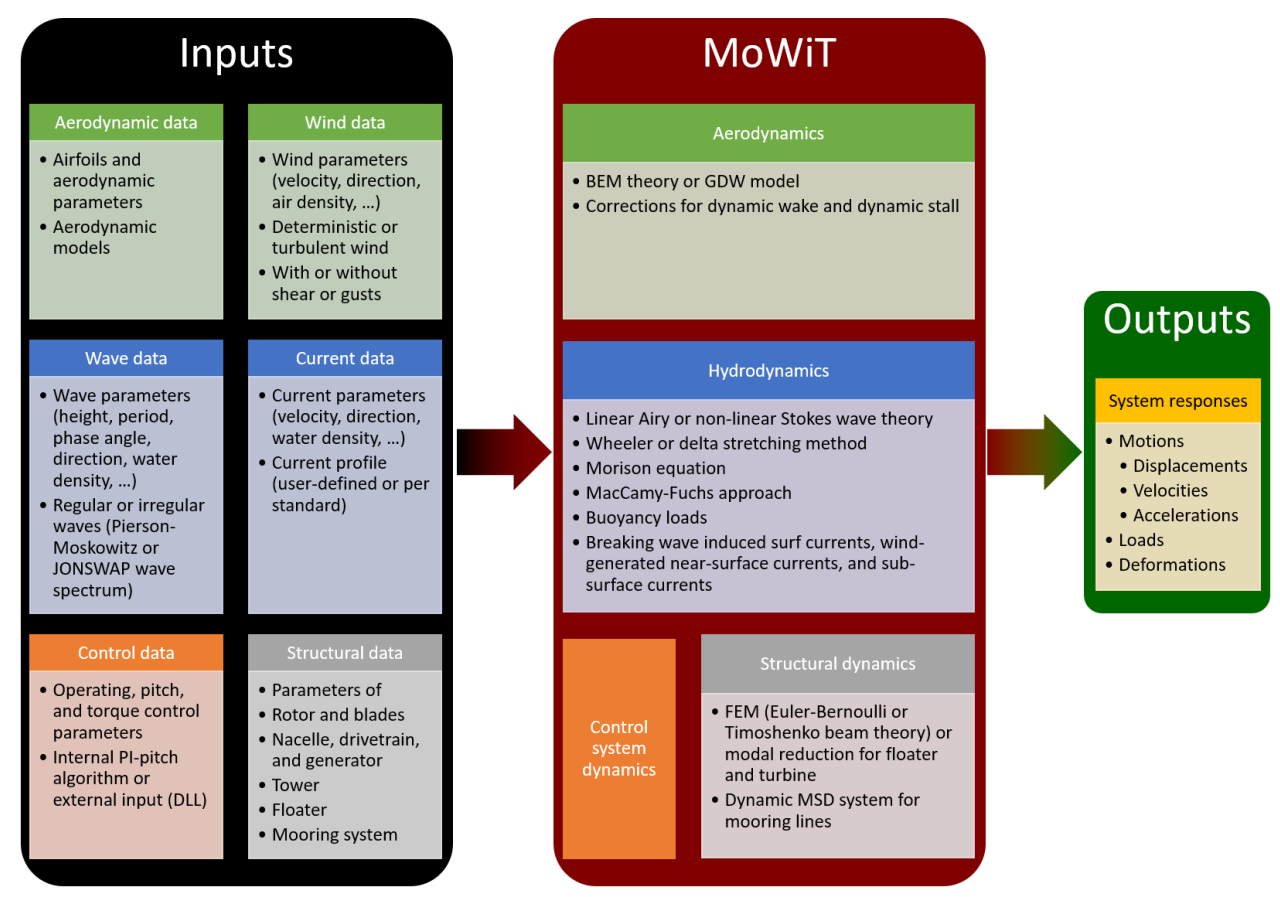

Figure 6. Flowchart representing the structure of the MoWiT model with inputs and outputs.

The simulations of models developed in the MoWiT library are performed in the time-domain and executed in Dymola. This simulation engine is highly suited for modeling complex systems, such as FOWTs, which come with a large number of system equations. Dymola provides various solvers with fixed or variable step size and following implicit or explicit method, to cope with a broad range of problems and system equation types. 


\subsection{Implementation of the OC3 FOWT in MoWiT}

The OC3 FOWT system is modeled in MoWiT according to the definitions given in References [8,22] and presented in Section 2. However, not all data relevant for modeling the system correctly are specified explicitly in these documents. Hence, in the following, the used, either prescribed or derived, parameters of the system components are addressed.

For the wind turbine, both the rotor and nacelle, as well as the operating control system, extensive data are available in Reference [22] and in Reference [8] for the adaptions made specifically for the OC3 spar-buoy floating wind turbine system. Thus, the entire RNA (modeled as flexible structure with modal reduced blades) and operating control can be implemented correctly in MoWiT according to the definitions. The comparison of the total RNA mass, presented in Table 4, shows perfect agreement.

The support structure model comprises tower and floater, as already mentioned in Section 3.1. Within the code-to-code comparisons of OC3 phase IV, the spar-buoy is considered as rigid structure throughout all load cases [7], which are introduced in Section 4.1. Only the tower was sometimes represented as rigid or flexible structure in the OC3 code-to-code comparisons. As the focus of the verification is on the floating platform, a rigid support structure model is utilized in MoWiT.

The structural part of the support structure, concerning the wind turbine tower, is described in depth in Reference [8], on which basis the tower with its distributed properties can be implemented from the top of the floating platform up to the RNA position through individual rigid cylindrical segments. The overall tower mass and corresponding center of mass are presented in Table 4 and compared to the specified values. There is just a minor deviation in the tower mass, which might be due to the fact that the tower is conical, however, each element is modeled as straight cylinder based on its averaged top and bottom diameter.

For the floating platform, however, only the main parameters for geometry, outer dimensions, as well as total mass and inertia properties are provided in Reference [8]. Other parameters, relevant for modeling the structure and its characteristics properly, such as cap and (distributed) wall thickness values, material properties, or any information regarding the ballast system, are missing, as already indicated in Section 2.1. To overcome this issue, the unavailable parameters are determined-in the following way and based on the assumptions described hereinafter-to match the existing data resulting for the total system, accordingly the resulting mass-related properties (Table 2), as good as possible.

- The floating platform, being part of the support structure model, is implemented as the tower through rigid cylindrical segments. As no distributed properties are available for the spar-buoy, four cylindrical bodies are used based on the geometry of the floater: (1) one for the bottom cylinder with given length and diameter; (2) one for the tapered part, as connection between the bottom and top cylinder, with determined length and averaged diameter of bottom and top cylinder; (3) one for the top cylinder with given length and diameter; and (4) one for modeling the ballast within the bottom cylinder.

- As no structural analysis is going to be carried out within the OC3 code-to-code comparisons, the cap thickness-meaning the thickness of the bottom cap of the bottom cylinder, as well as the thickness of the cap on the upper end of the top cylinder-is set equal to $1.0 \times 10^{-4} \mathrm{~m}$ to avoid large contribution of the caps to the total mass due to any too large assumed value.

- Each of the three structural cylinders (1)-(3), described in the first bullet point, is defined through its outer diameter and length, which are both provided or-in case of the tapered (2) part-determined as described beforehand, its wall thickness, as well as its material density. The latter two are assumed to be the same for the three cylindrical parts of the floating structure. As the platform inertia values are relevant for the dynamic response of the floating system, it is tried to match these inertia values as good as possible by modifying assumed values for the material density and wall thickness of the spar. First, it is presumed that the specified parameters for the inertia values are for the platform including ballast, because no separate values are given 
for the ballast and the total inertia is important for the dynamics. Furthermore, as it is not possible to match all (roll, pitch, and yaw) inertias at the same time under the assumptions made, it is focused on achieving correct values at least for the roll and pitch inertias, because these are usually more important than the yaw inertia.

The calculations are based on the target value search in Excel. The starting value for the material density is $7850 \mathrm{~kg} / \mathrm{m}^{3}$, assuming typical steel properties, and an upper bound is set at $10,000 \mathrm{~kg} / \mathrm{m}^{3}$. For the wall thickness, taking on one constant value for the entire platform for reasons of simplicity and as already mentioned above, the starting value is $0.1 \mathrm{~m}$, which is at the same time the upper bound. With these settings, the target value search results in a material density of $10,000 \mathrm{~kg} / \mathrm{m}^{3}$ and a wall thickness of $0.0314 \mathrm{~m}$. With these parameters, the difference in the platform roll and pitch inertias is with $1.58 \times 10^{-7} \%$ negligible, while the achieved yaw inertia is $43.57 \%$ smaller than the defined value, as presented in Table 2.

As the upper bound for the material density is reached, the target value search is again executed with removed upper limit. The result, however, is that an unfeasible high material density is reached, while the wall thickness would be unrealistically thin and the discrepancy between better matching the platform roll and pitch inertias, however, higher deviation in the yaw inertia becomes greater. Thus, the results obtained when limiting the material density to common and feasible values are kept.

A better match of the yaw inertia value could have been achieved by segmentation of the cylindrical structural elements of the spar-buoy. However, with unknown number of segments and length distributions, a full match of all inertia values at the same time is questionable to be obtained. Thus, as the focus in this paper is the verification of the modeling approach and implemented theories and coupled dynamics, a compromise is needed between available data and perfect match of resulting system properties. As mentioned above, the main focus is on the most important inertia components, namely for roll and pitch, and, hence, the discrepancy in the system yaw inertia is accepted and accounted for when analyzing the results of the code-to-code comparison, as covered in Section 5.

- Having the material density and wall thickness set, the ballast density and ballast height are determined to match the total platform mass including ballast of $7466.3 \mathrm{t}$, as specified in Table 2 . Due to the small difference in the tower mass, outlined before and in Table 4, the second criterion for determining the ballast parameters would either be

1. the same center of mass of platform including ballast at $89.9155 \mathrm{~m}$ below SWL;

2. or the same resulting center of mass of tower and platform including ballast at $85.6009 \mathrm{~m}$ below SWL;

3. or the same total restoring moment due to tower, platform, and ballast.

Due to the minor discrepancy in the tower mass, all three options for the second criterion yield very similar ballast parameters. Nevertheless, the second option to meet the same total center of mass is selected to avoid altering the response in pitch and roll by a shifted center of gravity. This results in a ballast density of $1907 \mathrm{~kg} / \mathrm{m}^{3}$ and a ballast height of $48.3708 \mathrm{~m}$, which yields a perfect match in the total platform mass and a minor deviation in the position of the center of mass of the floater, as presented in Table 2.

Table 5 summarizes the settings of the unavailable floater parameters, used for the modeling in MoWiT. With these settings, a resulting hydrostatic buoyancy force, determined based on the geometry and presuming a gravitational acceleration of $9.81 \mathrm{~m} / \mathrm{s}^{2}$, of $80,724,636 \mathrm{~N}$ is obtained. This deviates by $2.0 \times 10^{-2} \%$ from the specified value, mentioned in Section 2.1 , what is mainly expected to come from a slightly different gravitational acceleration value taken in the OC3 phase IV definition. The hydrostatic restoring is, as opposed to the OC3 system definition in Reference [8], not explicitly defined within the MoWiT model but a result of the implemented system properties. Hence, 
a quantitative comparison of the hydrostatic restoring values is not possible. However, the precise representation of the floater geometry and its center of mass allow to draw conclusions on the correct representation of the hydrostatic restoring. This as well can be examined indirectly when analyzing the simulation results. In contrast to the hydrostatic restoring values, the additional damping parameters, outlined in Section 2.1 and stated in Reference [8], are implemented separately in MoWiT and the hydrodynamic coefficients are set according to the definitions.

Table 5. Assumed values of the undefined spar-buoy and system parameters.

\begin{tabular}{lcc}
\hline Parameter & Symbol & Value \\
\hline Cylinder cap thickness & $t_{\text {cap }}$ & $1.0 \times 10^{-4} \mathrm{~m}$ \\
Top cylinder wall thickness & $t_{\mathrm{TC}}$ & $0.0314 \mathrm{~m}$ \\
Bottom cylinder wall thickness & $t_{\mathrm{BC}}$ & $0.0314 \mathrm{~m}$ \\
Density of the platform material & $\rho_{\text {platform }}$ & $10,000 \mathrm{~kg} / \mathrm{m}^{3}$ \\
Density of the ballast material & $\rho_{\text {ballast }}$ & $1907 \mathrm{~kg} / \mathrm{m}^{3}$ \\
Height of ballast within the bottom cylinder & $h_{\text {ballast }}$ & $48.3708 \mathrm{~m}$ \\
Gravitational acceleration & $g$ & $9.81 \mathrm{~m} / \mathrm{s}^{2}$ \\
\hline
\end{tabular}

The mooring system properties, including as well the additional yaw spring stiffness specified in Reference [8] and mentioned in Section 2.1 are implemented in the MoWiT model according to the definitions.

Finally, the OC3 spar-buoy FOWT model, implemented as described above in the MoWiT library, is simulated in Dymola. The specific simulation and solver settings are stated in Section 4.1 for each simulation case separately. A visualization of the modeled system is shown in Figure 5.

\section{Code-to-Code Comparison}

To verify the OC3 spar-buoy FOWT system model, implemented in MoWiT as described in Section 3, the load case (LC) simulations are executed with the MoWiT model and the code-to-code comparison is performed, as done in the OC3 project [7], for comparing and verifying the results obtained with the MoWiT model. Hereinafter, first (Section 4.1), the simulated LCs are presented together with the settings used in Dymola for executing the simulations, while in the subsequent Section 4.2 the results of the simulations with the MoWiT model are presented in comparison with the other code results from the OC3 project. Further discussion and analyses of these results follow in Section 5 .

\subsection{Simulated Load Cases}

For the analyses of offshore wind turbine systems, various design load cases are recommended by standards [41-45]. Based on these guidelines, only a reduced number of design relevant LCs and environmental conditions are selected for the application in research studies [46-48]. Within phase IV of OC3, a separate set of LCs is specified, which is grouped into three categories: (1) LC 1.x for system-only analyses; (2) LC 4.x for hydro-elastic response analyses, hence, only with waves; and (3) LC 5.x for aero-hydro-servo-elastic response analyses, thus, with environmental impact from both wind and waves [7]. To allow a code-to-code comparison of the spar-buoy FOWT model in MoWiT with the other codes and tools used in the OC3 project, the same LCs are simulated with the implemented model as presented in Section 3.2.

\subsubsection{LC 1.x}

In the LCs for system-only analyses, neither wind nor waves are considered. Hence, the air density is set equal to $0 \mathrm{~kg} / \mathrm{m}^{3}$ in order to have no aerodynamic loads acting, and still water condition is applied so that no waves exist. For the wind turbine control and operating system, the brake is active and the control is disabled. In the OC3 phase IV code-to-code comparisons, the entire wind turbine 
system is modeled as a rigid structure, which is as well realized in the MoWiT model, as described in Section 3.2. Case-specific simulation configurations, with additional choices (highlighted in red) for undefined settings are summarized in Table 6. Thus, in addition to the six free-decay tests LC 1.4a to $1.4 \mathrm{f}$ with initial deflections in one of the six degrees of freedom taken as starting position of the floater, which are as well utilized for the evaluation of the eigenanalysis (LC 1.2), one "neutral" free-decay test without any initial deflection is simulated to be used for determining the static equilibrium (LC 1.3). All simulations in the LC group 1.x are executed in Dymola, using the Rkfix4 (Runge-Kutta fixed-step and 4th order method) solver with a fixed integrator step-size of $0.01 \mathrm{~s}$. The output interval length of the resulting time series amounts to $0.05 \mathrm{~s}$.

Table 6. Simulation settings and analysis methods for load case (LC) group 1.x, assumptions and modifications are written in red.

\begin{tabular}{|c|c|c|c|c|c|}
\hline LC & Type & \multicolumn{2}{|c|}{ Initial Conditions } & Simulation Length & Analyzed Output for Code-to-Code Comparison \\
\hline 1.2 & Eigenanalysis & $\mathrm{N} / \mathrm{A}$ & & $\mathrm{N} / \mathrm{D}$ & taken from LC 1.4a-f \\
\hline 1.3 & Static equilibrium & $\mathrm{N} / \mathrm{A}$ & & $\mathrm{N} / \mathrm{D}$ & Static equilibrium taken from LC 1.4 at $600 \mathrm{~s}$ \\
\hline 1.4 & Free-decay & & & $600 \mathrm{~s}$ & Time series \\
\hline a & & Surge: & $21 \mathrm{~m}$ & & \\
\hline $\mathrm{b}$ & & Sway: & $18 \mathrm{~m}$ & & \\
\hline $\mathrm{c}$ & & Heave: & $5 \mathrm{~m}$ & & \\
\hline $\mathrm{d}$ & & Roll: & $-10^{\circ}$ & & \\
\hline $\mathrm{e}$ & & Pitch: & $10^{\circ}$ & & \\
\hline $\mathrm{f}$ & & Yaw: & $-6^{\circ}$ & & \\
\hline
\end{tabular}

\subsubsection{LC 4.x}

In the LC group 4.x only the hydro-elastic response should be analyzed. Hence, the aerodynamics are turned off by setting again the air density equal to $0 \mathrm{~kg} / \mathrm{m}^{3}$. The brake is still enabled and the control switched off. Contrary to the OC3 phase IV definition in Reference [7] that the tower is considered to be flexible, not only the floater, but the entire FOWT system is modeled as rigid structure in MoWiT, as spar-buoy and tower are implemented as one continuous structure in MoWiT, which is already pointed out in Section 3.2. The two LCs in group 4.x differ in the considered wave type, as presented in Table 7. The regular wave is defined through the wave theory, wave height $H$, and wave period $T$, while the irregular wave is specified by the wave theory and spectrum type used, as well as the significant wave height $H_{\mathrm{s}}$ and peak period $T_{\mathrm{p}}$. As nothing specifically is stated for the hydrodynamic load calculation, the more sophisticated MCF approach, as well as the Wheeler stretching, are applied in MoWiT. Both LCs, for which no initial conditions are required, are simulated in Dymola, using the same integration, solver, and output settings as in the LC group 1.x, described in Section 4.1.1, namely Rkfix 4 solver with fixed integrator step-size of $0.01 \mathrm{~s}$ and $0.05 \mathrm{~s}$ output interval length.

Table 7. Simulation settings and analysis methods for LC group 4.x, assumptions are written in red.

\begin{tabular}{ccccll}
\hline LC & Type & Wave Conditions & Simulation Length & Analyzed Output for Code-to-Code Comparison \\
\hline 4.1 & $\begin{array}{c}\text { Regular } \\
\text { waves }\end{array}$ & $\begin{array}{c}\text { Airy wave theory } \\
\text { H=6 m; } T=10 \mathrm{~s}\end{array}$ & $120 \mathrm{~s}$ & Time series \\
4.2 & $\begin{array}{c}\text { Irregular } \\
\text { waves }\end{array}$ & $\begin{array}{c}\text { Airy wave theory } \\
\text { JONSWAP spectrum } \\
\end{array}$ & $600 \mathrm{~s}$ & $\begin{array}{l}\text { min, mean, max, stdev } \\
\text { Power spectra }\end{array}$ & taken from last $120 \mathrm{~s}$ \\
& & & & taken from entire $600 \mathrm{~s}$ \\
\hline
\end{tabular}

\subsubsection{LC 5.x}

Finally, the LC group 5.x represents full aero-hydro-servo-elastic simulations. Hence, the air density is now set equal to $1.225 \mathrm{~kg} / \mathrm{m}^{3}$-based on the offshore aerodynamic properties specified for the NREL 5 MW wind turbine [22] - and the operating control system is turned on. The wind is either considered to be constant with a specified wind speed $V_{\text {hub }}$ at hub height, or turbulent, defined additionally through the turbulence model and turbulence intensity $I_{\text {ref }}$. Contrary to the OC3 
specification [7], which uses the Mann turbulent wind model, the turbulent wind time series in MoWiT follows the Kaimal model as it can easily be generated by means of TurbSim [49], which only supports Kaimal or von Karman normal turbulence models. The waves and hydrodynamic load calculations are realized just like in the LC group 4.x, described in Section 4.1.2. The specific parameter settings for the different LCs are presented in Table 8. As defined in OC3 phase IV [7] for both LC groups 4.x and $5 . x$, the tower is originally considered to be flexible; however, it is modeled in MoWiT together with the spar-buoy as rigid structure, while the RNA is implemented as flexible structure as prescribed. For the LC 5.1 simulation the same integration, solver, and output settings as in the LC groups 1.x and 4.x are used (solver: Rkfix4, fixed integrator step-size: $0.01 \mathrm{~s}$, output interval length: $0.05 \mathrm{~s}$ ), while for LC 5.2 and 5.3, which both deal with turbulent wind and irregular waves, the variable-step Cvode (C-language variable-coefficients ordinary differential equation) solver with tolerance of $1.0 \times 10^{-4}$ is utilized. Originally, there was also a fourth LC (5.4) defined in phase IV of OC3 for generating effective response amplitude operators [7], which, however, was not employed in the code-to-code comparison with the MoWiT model in this study.

Table 8. Simulation settings and analysis methods for LC group 5.x, assumptions and modifications are written in red.

\begin{tabular}{|c|c|c|c|c|c|}
\hline LC & Wind Conditions & Wave Conditions & $\begin{array}{c}\text { Initial } \\
\text { Conditions }\end{array}$ & $\begin{array}{l}\text { Simulation } \\
\text { Length }\end{array}$ & $\begin{array}{l}\text { Analyzed Output for } \\
\text { Code-to-Code Comparison }\end{array}$ \\
\hline 5.1 & $\begin{array}{c}\text { Steady, uniform wind } \\
V_{\text {hub }}=8 \mathrm{~m} / \mathrm{s}\end{array}$ & $\begin{array}{c}\text { Regular Airy waves } \\
H=6 \mathrm{~m} ; T=10 \mathrm{~s}\end{array}$ & $\begin{array}{l}\text { Rotor speed: } \\
9 \mathrm{rpm}\end{array}$ & $120 \mathrm{~s}$ & Time series \\
\hline 5.2 & $\begin{array}{c}\text { Turbulent wind } \\
\text { (Mann) Kaimal model } \\
V_{\text {hub }}=11.4 \mathrm{~m} / \mathrm{s} \\
I_{\text {ref }}=0.14\end{array}$ & $\begin{array}{l}\text { Irregular Airy waves } \\
\text { JONSWAP spectrum } \\
H_{\mathrm{s}}=6 \mathrm{~m} ; T_{\mathrm{p}}=10 \mathrm{~s}\end{array}$ & $\begin{array}{l}\text { Rotor speed: } \\
12 \mathrm{rpm}\end{array}$ & $\begin{array}{l}(600 s) \\
650 \mathrm{~s}\end{array}$ & $\begin{array}{l}\text { min, mean, max, stdev } \\
\text { taken from last } 120 \mathrm{~s} \\
\text { Power spectra } \\
\quad \text { taken from last } 600 \mathrm{~s}\end{array}$ \\
\hline 5.3 & $\begin{array}{c}\text { Turbulent wind } \\
\text { (Mann) Kaimal model } \\
V_{\text {hub }}=18 \mathrm{~m} / \mathrm{s} \\
I_{\text {ref }}=0.14\end{array}$ & $\begin{array}{c}\text { Irregular Airy waves } \\
\text { JONSWAP spectrum } \\
H_{\mathrm{s}}=6 \mathrm{~m} ; T_{\mathrm{p}}=10 \mathrm{~s}\end{array}$ & $\begin{array}{c}\text { Rotor speed: } \\
12 \mathrm{rpm} \\
\text { Blade pitch: } \\
15^{\circ}\end{array}$ & $\begin{array}{c}(600 \mathrm{~s}) \\
650 \mathrm{~s}\end{array}$ & $\begin{array}{l}\text { min, mean, max, stdev } \\
\text { taken from last } 120 \mathrm{~s} \\
\text { Power spectra } \\
\text { taken from last } 600 \mathrm{~s}\end{array}$ \\
\hline
\end{tabular}

\subsection{Results of the Simulations and the Code-to-Code Comparison}

For the comparison of the LC simulation results only a few results are presented, mostly based on the selection in the OC3 code-to-code comparison [7]. An overview of the different codes, tools, and modeling approaches used by the OC3 phase IV participants [7] and described in Section 1 is given in Figure 1, including as well the color-coding, used for comparing the results from the ten OC3 phase IV participants. In addition to the theories and modeling approaches mentioned in Section 3.1, stream functions or Airy wave theory with free surface connections, indicated by Airy+, as well as linear potential flow $(\mathrm{PF})$ theory with radiation and diffraction are utilized to deal with the hydrodynamics. The MCF approach, used in MoWiT for taking diffraction effects into account, applies as well PF theory. Regarding the control system, two more options are available in the OC3 phase IV participants' codes: either the implementation through an user-defined (UD) subroutine, or the interface to Simulink with MATLAB (SM). The structural dynamics of turbine and mooring system can be formulated by means of multibody-dynamics (MBD). For the turbine dynamics, FEM could as well be used just for mode preprocessing (FEMP). Finally, the quasi-static catenary equation (QSCE) and implementation through user-defined force-displacement (UDFD) relationships provide two more options for modeling the mooring system dynamics [7].

In the following, the results are mainly presented by plots and comparison of numbers. The more detailed discussion on reasons for differences, as well as performed in-depth analyses follow in Section 5 . 


\subsubsection{Results for LC 1.x}

From the full-system eigenanalysis LC 1.2 , both the natural frequencies $f_{\text {nat }}$ and the damping ratios $\zeta$ in the six degrees of freedom (DOFs) surge, sway, heave, roll, pitch, and yaw are compared. These, however, as mentioned in Table 6, are taken from analysis of the free-decay time series from LCs 1.4a to 1.4f. The natural frequencies obtained with MoWiT could be compared with nine other codes, whereas results for the damping ratios are only available from three OC3 participants, as presented both in Figure 7. In general, it can be seen that the MoWiT-based results are within the limits of the results from the OC3 participants, with just some minor differences in the surge and sway natural frequencies and some higher deviations in the yaw natural frequency and the damping ratio in heave. A more in depth comparison, based on numerical values and including analyses and justification of the deviations, is given in Section 5.1.
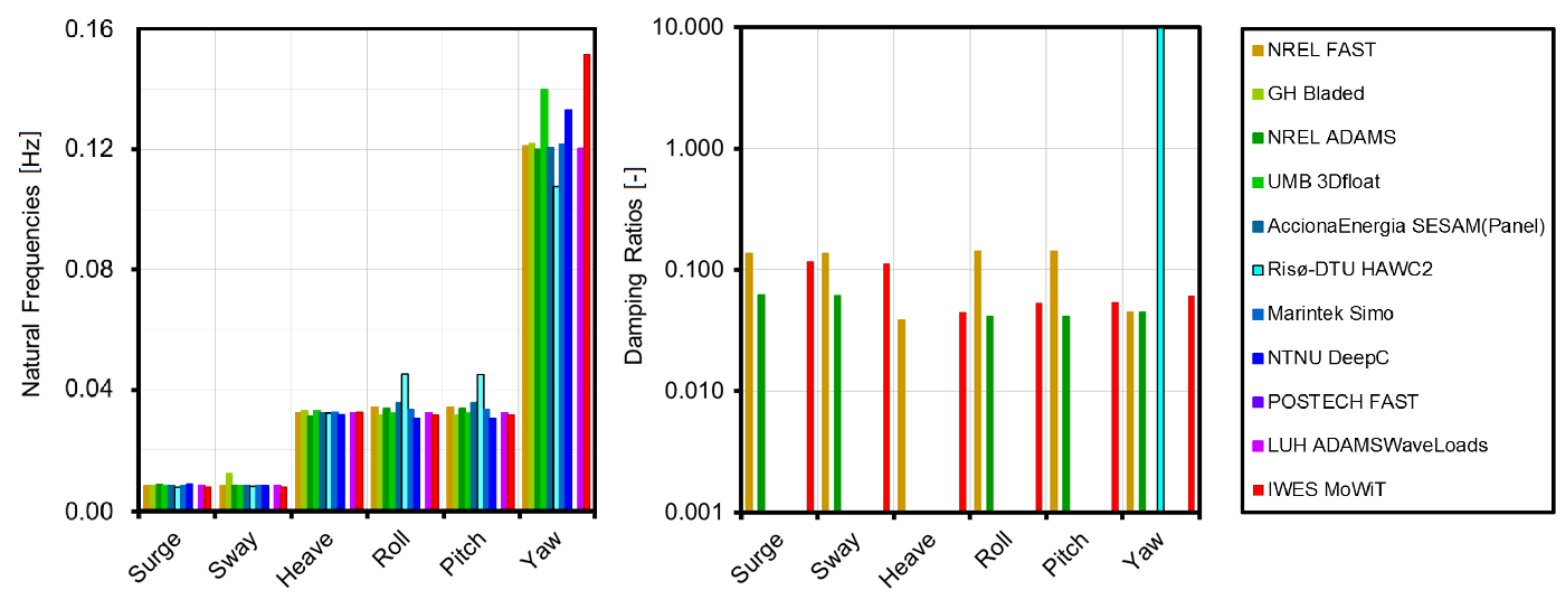

Figure 7. Full-system hydro-elastic natural frequencies and damping ratios.

The results for the static equilibrium analysis, which are obtained from the "neutral" free-decay simulation in LC 1.4 at the end of the simulation time, are only presented in numerical format in Table 11 in Section 5.1 and show, except for the heave DOF, good agreement with the results from the OC3 phase IV participants.

The time series of the free-decay simulations are presented in Figures 8-10 for LCs 1.4a, 1.4c, and 1.4e for the responses in the surge, heave, and pitch DOFs, as well as in Figure $11 \mathrm{for}$ LC $1.4 \mathrm{f}$ for the response in the yaw DOF. The time series represent very well the above mentioned findings from the natural frequencies, damping ratios, and static equilibrium analyses, and show also couplings in the responses of different DOFs. 

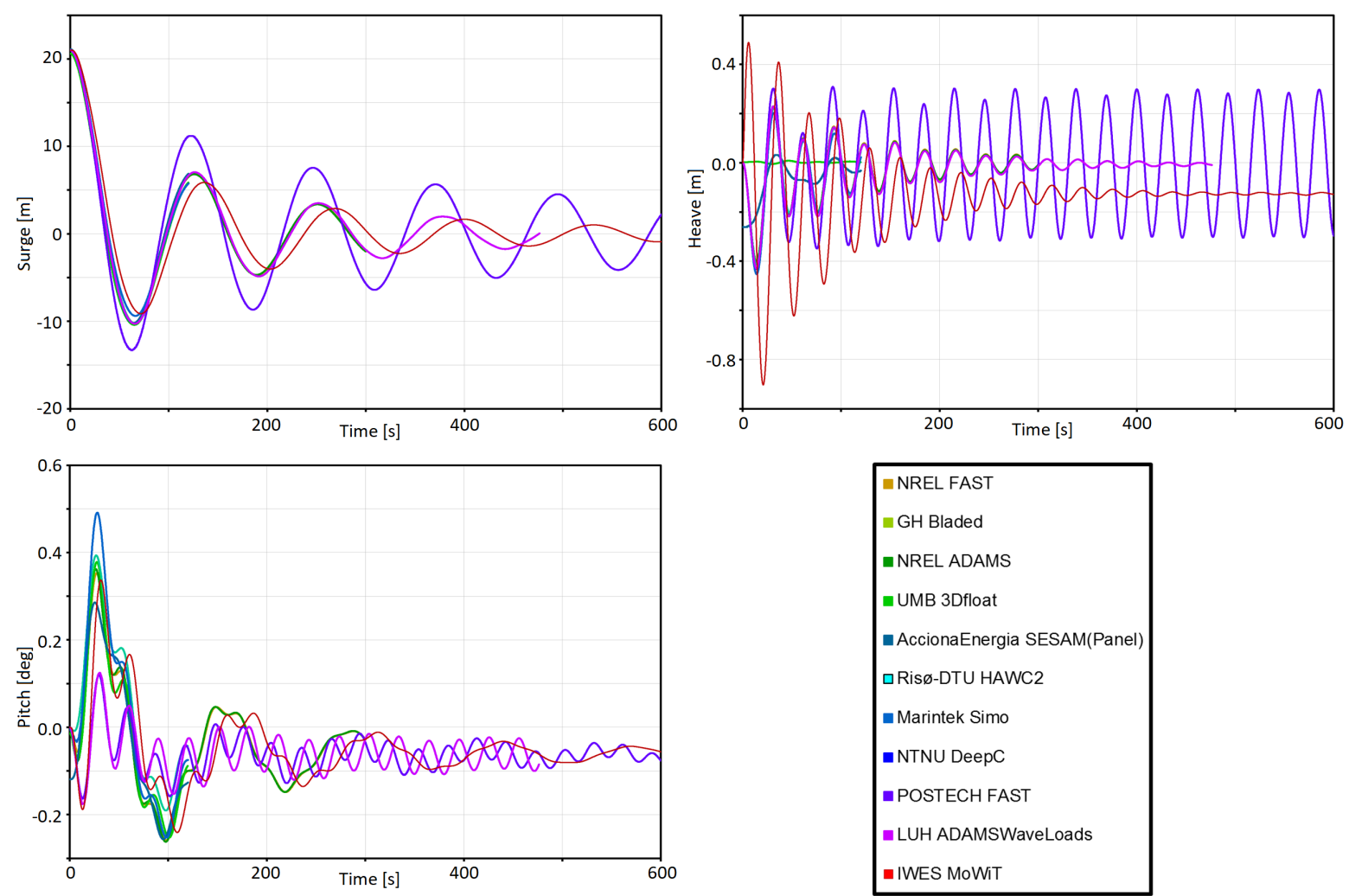

\begin{tabular}{|l|}
\hline - NREL FAST \\
- GH Bladed \\
- NREL ADAMS \\
- UMB 3Dfloat \\
- AccionaEnergia SESAM(Panel) \\
-Risø-DTU HAWC2 \\
- Marintek Simo \\
- NTNU DeepC \\
- POSTECH FAST \\
- LUH ADAMSWaveLoads \\
- IWES MoWIT
\end{tabular}

Figure 8. Free-decay time series in platform surge from LC 1.4a.
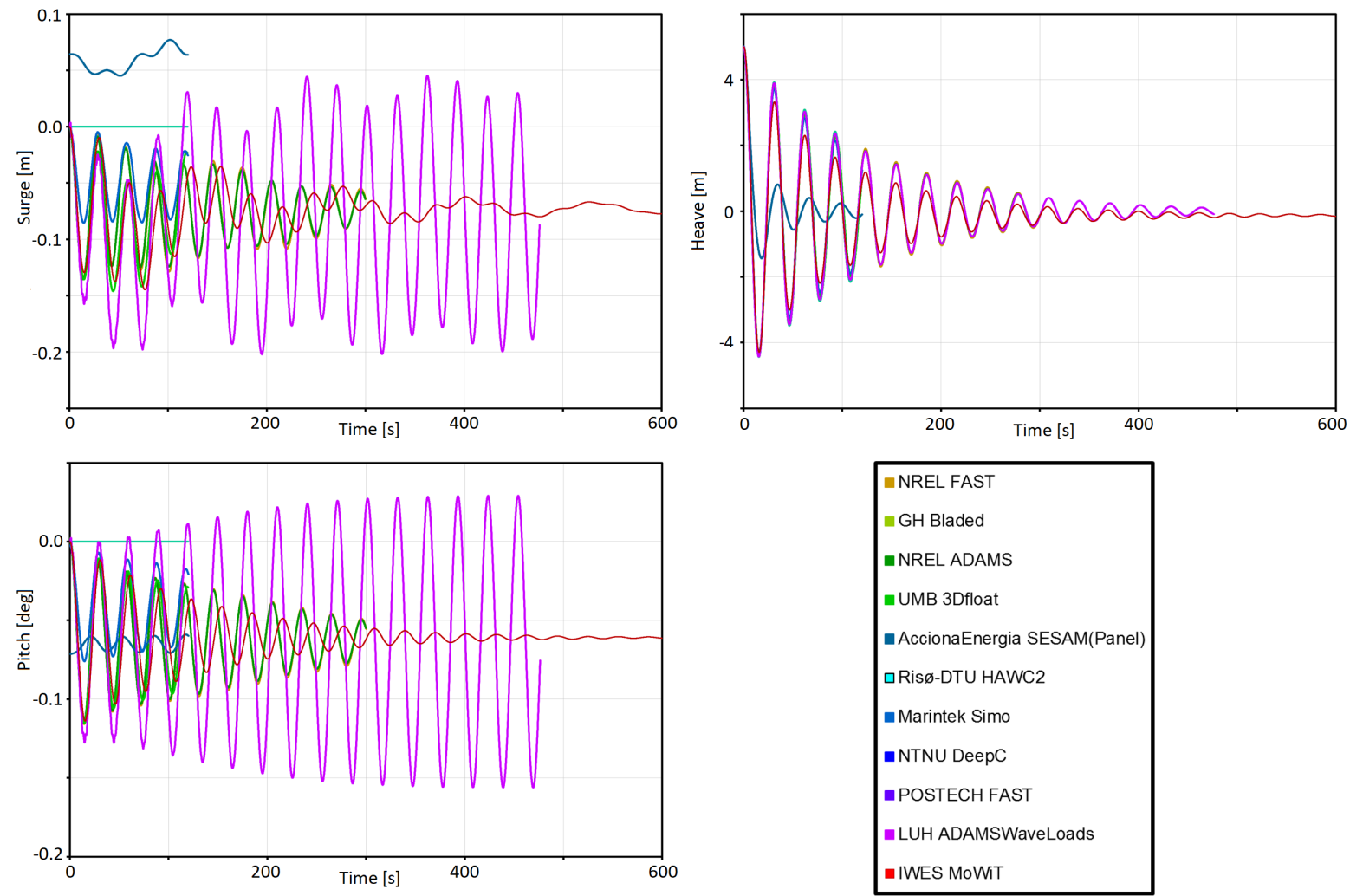

- NREL FAST
$=$ GH Bladed
- NREL ADAMS
- UMB 3Dfloat
- AccionaEnergia SESAM(Panel)
םRisø-DTU HAWC2
- Marintek Simo
- NTNU DeepC
- POSTECH FAST
- LUH ADAMSWaveLoads
- IWES MoWIT

Figure 9. Free-decay time series in platform heave from LC 1.4c. 

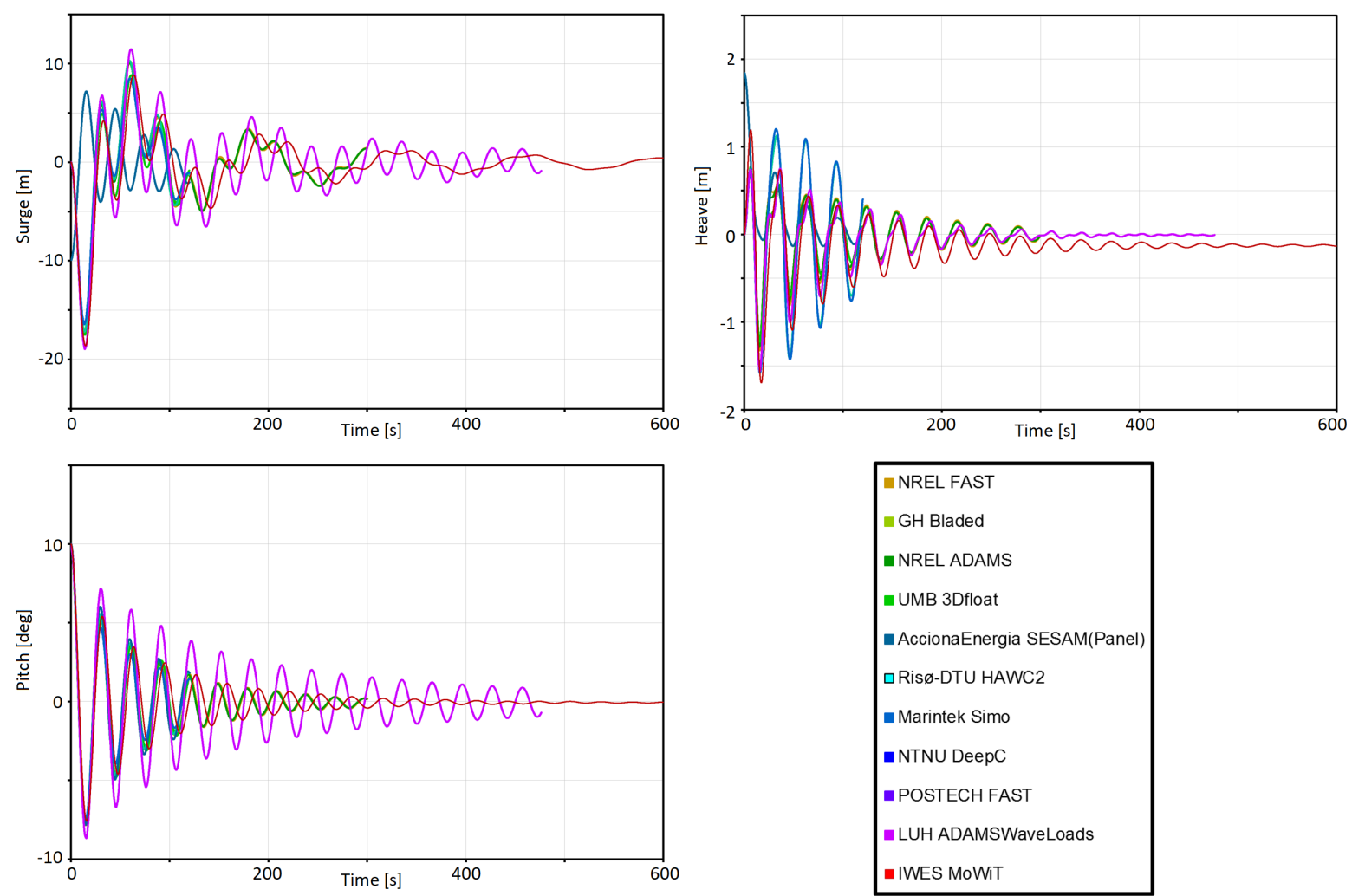

Figure 10. Free-decay time series in platform pitch from LC 1.4e.
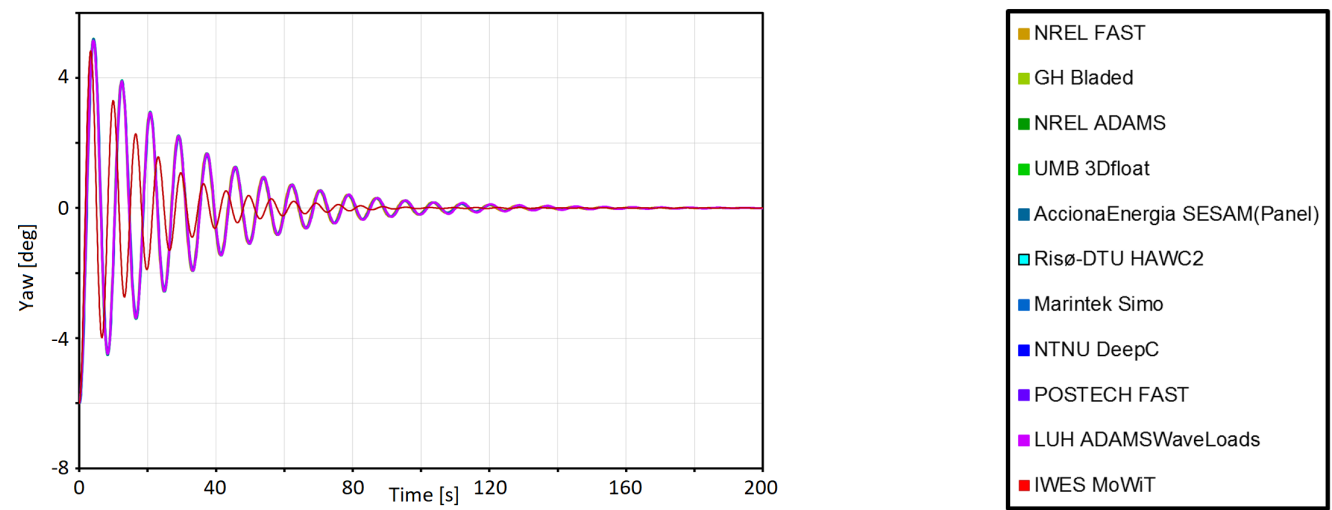

Figure 11. Free-decay time series in platform yaw from LC 1.4f.

\subsubsection{Results for LC 4.x}

For the hydro-elastic response analyses in LC group 4.x, first, the simulations with regular waves are presented. These comprise time series for the surge, heave, and pitch DOFs (Figure 12a-c, as well as for the downstream fairlead tension (Figure 12f). Originally also tower-top fore-aft deflection and shear force are compared within the OC3 phase IV activities; however, as the tower is modeled throughout the LCs together with the spar-buoy floater as rigid structure in MoWiT, no tower-top deflections are obtained. Hence, in addition to the tower-top fore-aft shear force (Figure 12d), also the tower-top fore-aft bending moment is presented (Figure 12e). For the latter two, the MoWiT results match the time series from the OC3 phase IV participants, while more motion is seen in the platform DOFs, as well as the downstream fairlead tension. This behavior is analyzed and discussed in more detail in Section 5.2. 


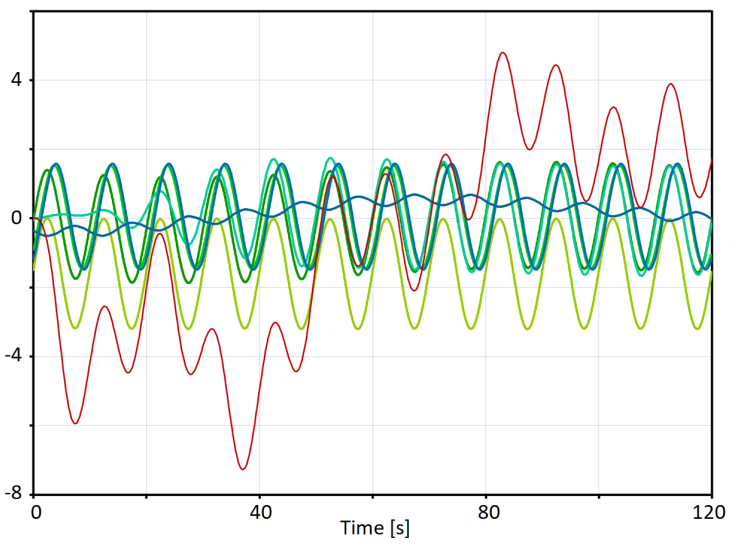

(a) Platform surge motion [m].

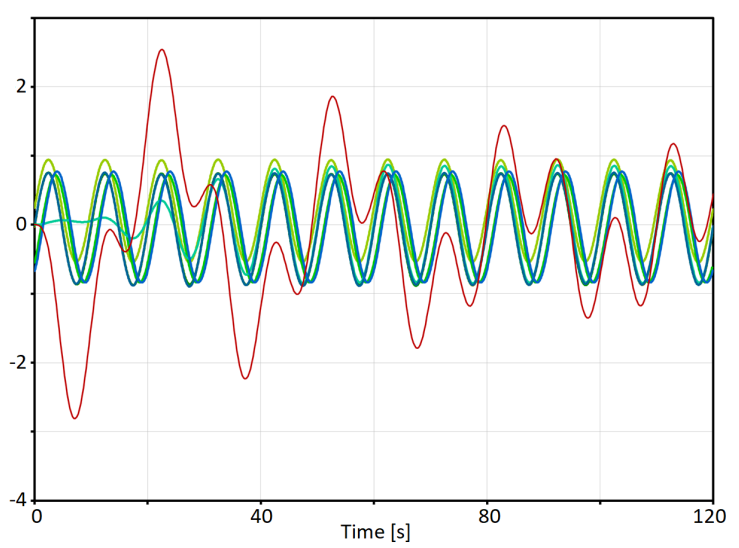

(c) Platform pitch motion [deg].

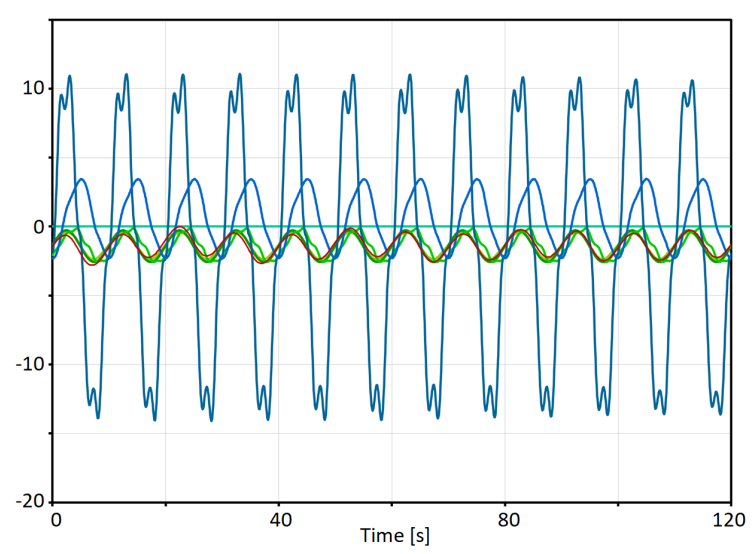

(e) Tower-top fore-aft bending [MNm].

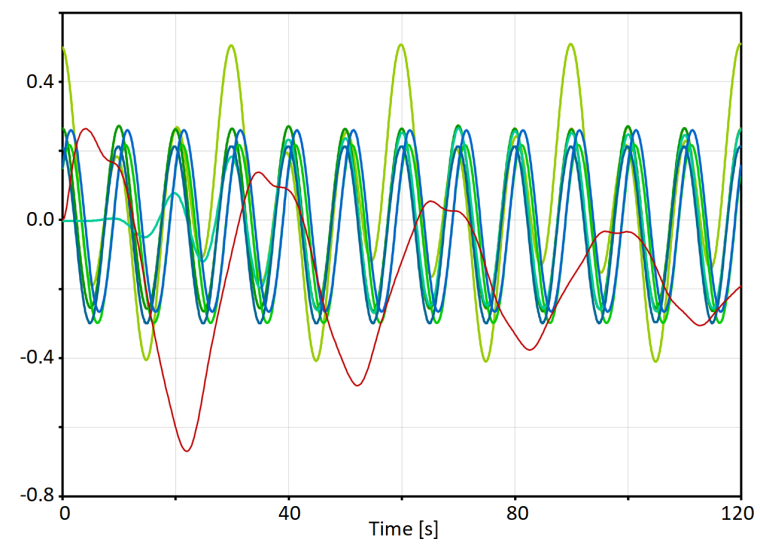

(b) Platform heave motion [m].

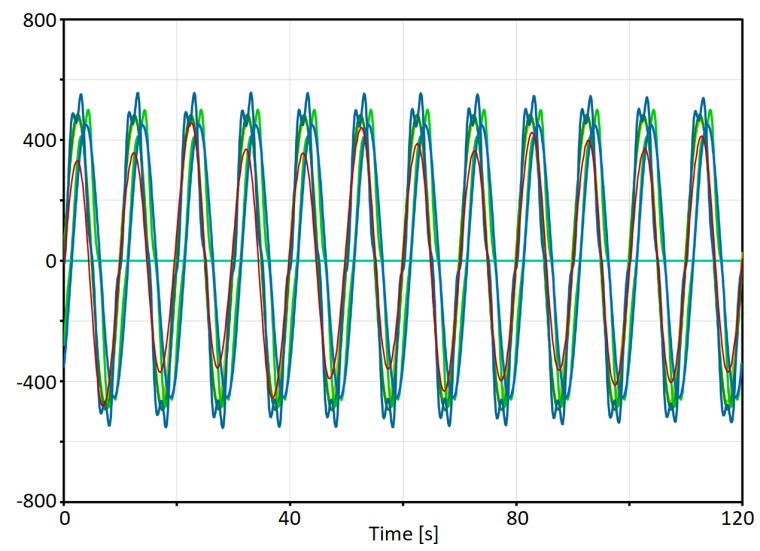

(d) Tower-top fore-aft shear force [kN].

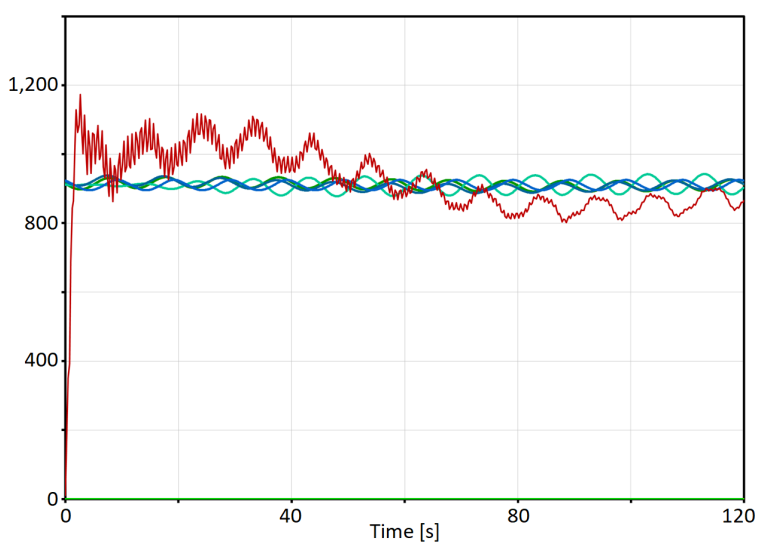

(f) Downstream fairlead tension [kN].

\begin{tabular}{|c|c|c|c|c|c|}
\hline NREL FAs & $\approx$ GH Bladed & $=$ NREL ADAMS & UMB 3Dfloat & - AccionaEnergia SESAM(P & \\
\hline$\square$ Risø-DTU HAWC2 & - Marintek Simo & - NTNU DeepC & - POSTECH FAST & - LUH ADAMSWaveLoads & —IWES MoWIT \\
\hline
\end{tabular}

Figure 12. Hydro-elastic time series with regular waves from LC 4.1.

For the hydro-elastic response analyses with irregular waves from LC 4.2, the statistics are taken from the final fifth of the time series, while the power spectra are generated by using the entire length of the simulation, as indicated in Table 7. Figure 13 demonstrates the power spectra for the same parameters as considered already in LC 4.1 for presentation of the results. The comparison of the statistics of the time series shows good agreement between MoWiT and the OC3 results for the tower-top fore-aft shear force and bending, as well as the downstream fairlead tension; however, 
the statistics for the platform motions from MoWiT yield overall some smaller values by amount. The platform motions response spectra, on the other hand, match the power spectra from the OC3 participants for frequencies below the irregular wave frequency. For higher frequencies, as well as for the response spectra of the other parameters, there are significant deviations between the codes. In-depth analyses of these are given in Section 5.2.

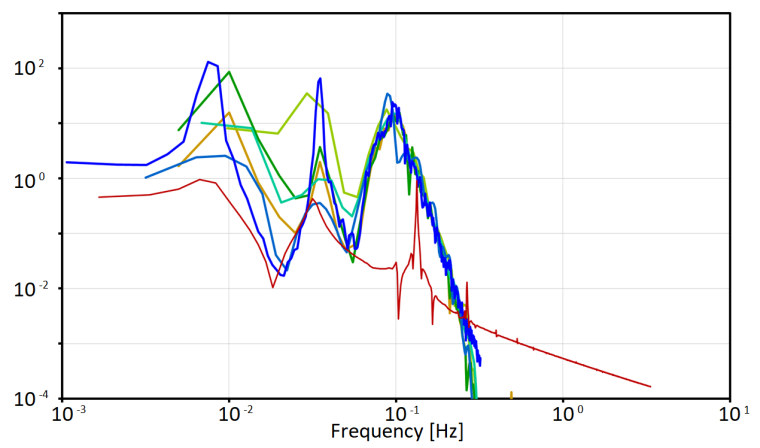

(a) Platform surge motion $\left[\mathrm{m}^{2} / \mathrm{Hz}\right]$.

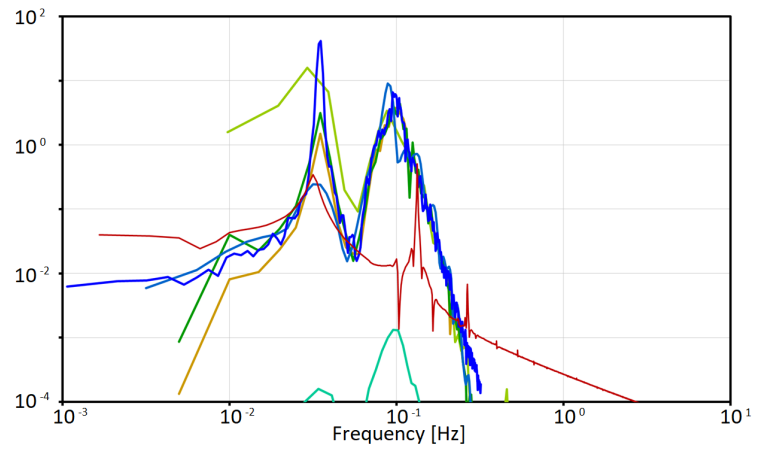

(c) Platform pitch motion $\left[\mathrm{deg}^{2} / \mathrm{Hz}\right]$.

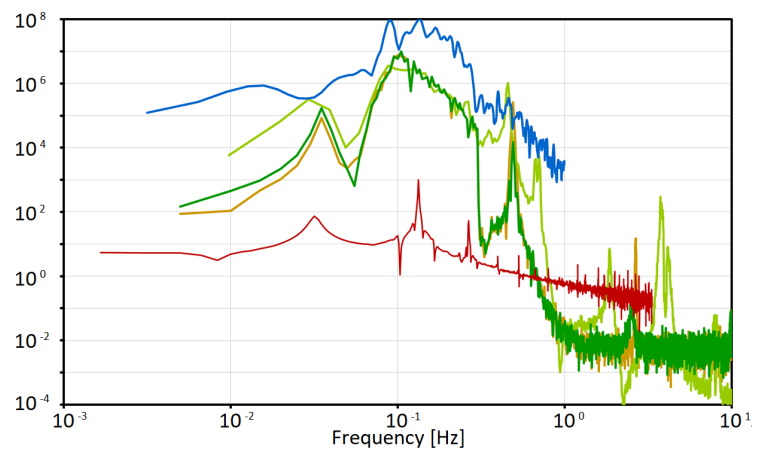

(e) Tower-top fore-aft bending $\left[(\mathrm{kNm})^{2} / \mathrm{Hz}\right]$.

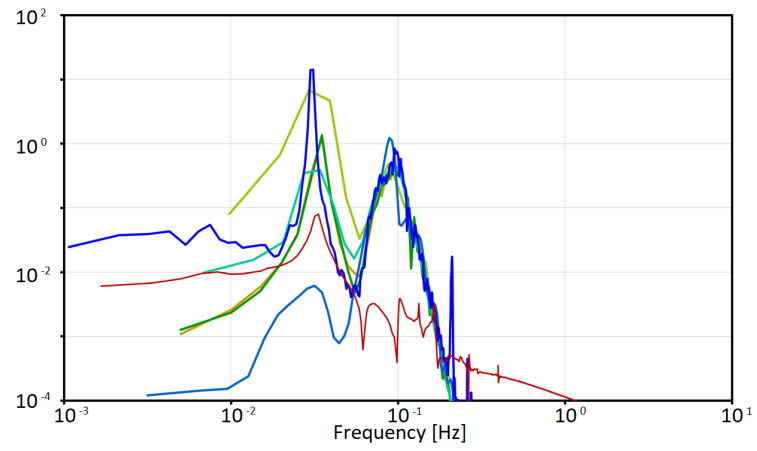

(b) Platform heave motion $\left[\mathrm{m}^{2} / \mathrm{Hz}\right]$.

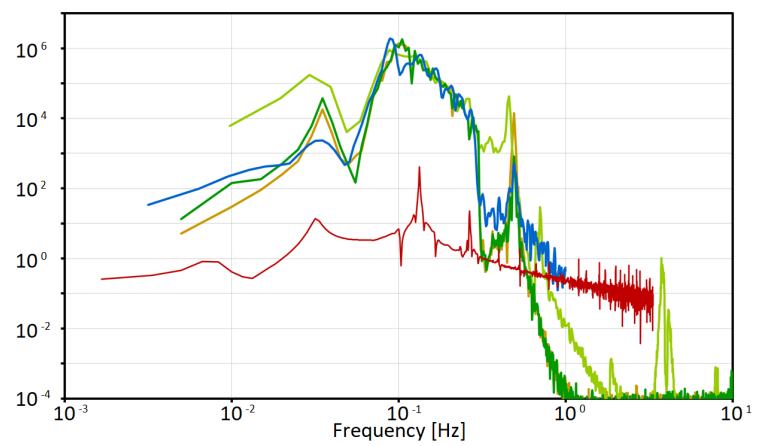

(d) Tower-top fore-aft shear force $\left[\mathrm{kN}^{2} / \mathrm{Hz}\right]$.

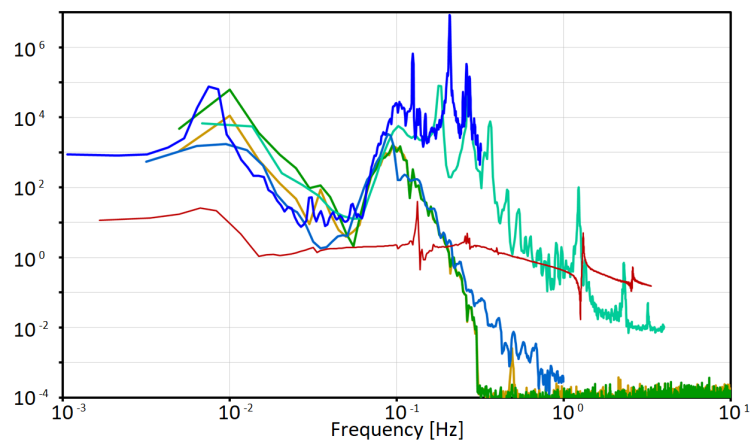

(f) Downstream fairlead tension $\left[\mathrm{kN}^{2} / \mathrm{Hz}\right]$.

\begin{tabular}{|c|c|c|c|c|}
\hline & & DAMS & - UMB 3Dfloat & e) \\
\hline $\mathrm{HA}$ & Marintek Simo & NTNU DeepC & POSTECH FAST & - LUH ADAMSWaveLoads \\
\hline
\end{tabular}

Figure 13. Hydro-elastic power spectra with irregular waves from LC 4.2.

\subsubsection{Results for LC 5.x}

In the LC group 5.x, the aero-hydro-servo-elastic response of the FOWT system is analyzed firstly under regular conditions, and then for irregular waves and turbulent wind. Beginning with the regular waves and steady wind case LC 5.1, the time series of the parameters considered already in LC 4.x (namely the surge, heave, and pitch DOFs, the tower-top fore-aft shear force and bending moment, as well as the downstream fairlead tension) and additionally the upstream fairlead tension, the generator power and the rotor speed, as well as the out-of-plane blade-tip deflection are presented in Figures 14 
and 15. The MoWiT time series for the tower-top fore-aft shear force and bending moment, the out-of-plane blade-tip deflection, the generator power and rotor speed, the platform pitch and yaw motions, as well as the downstream and upstream fairlead tensions are comparable to the OC 3 phase IV participants' results with more or less long lasting deviations at the beginning of the time series. However, larger discrepancies are observed in the platform surge and heave motions time series. These findings are discussed in-depth and reasoned in Section 5.3.

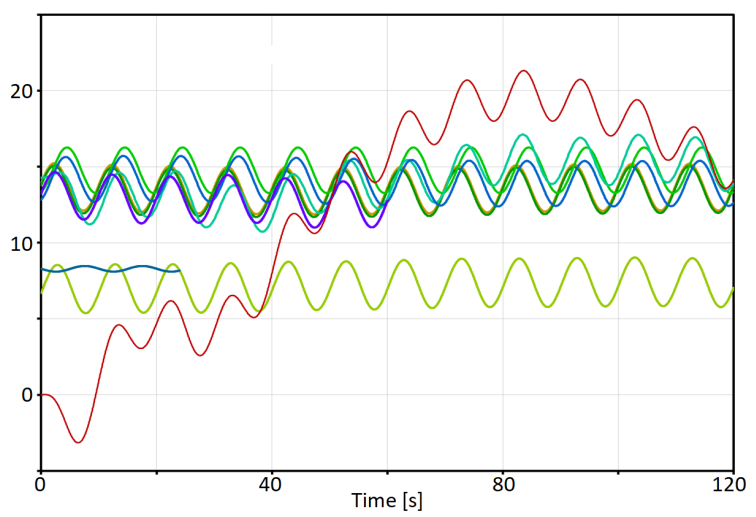

(a) Platform surge motion [m].

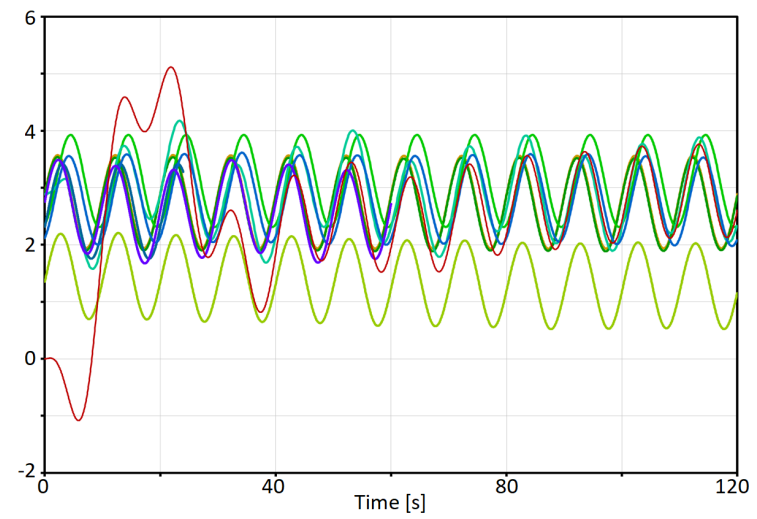

(c) Platform pitch motion [deg].

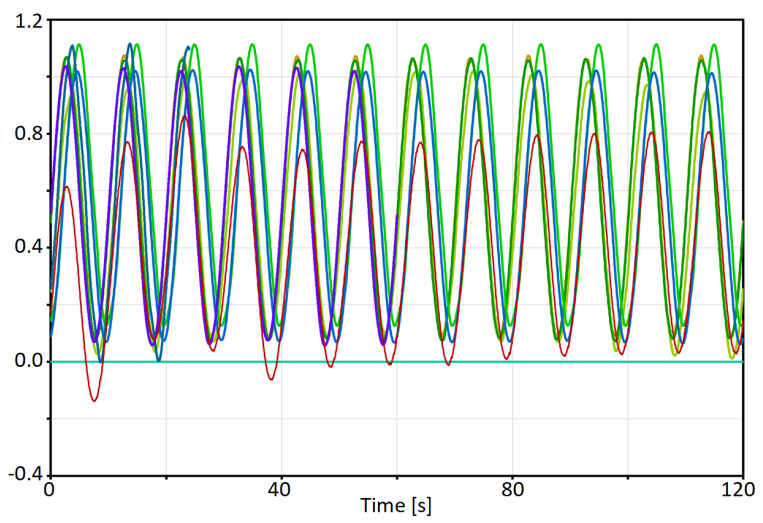

(e) Tower-top fore-aft shear force [MN].

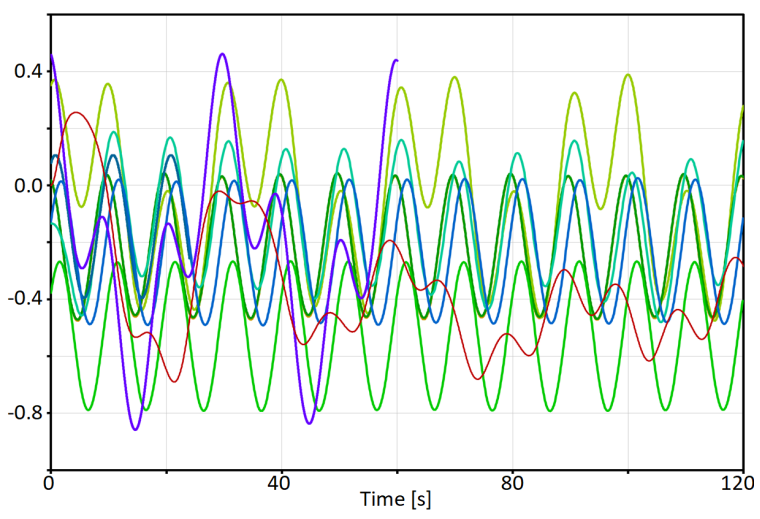

(b) Platform heave motion [m].

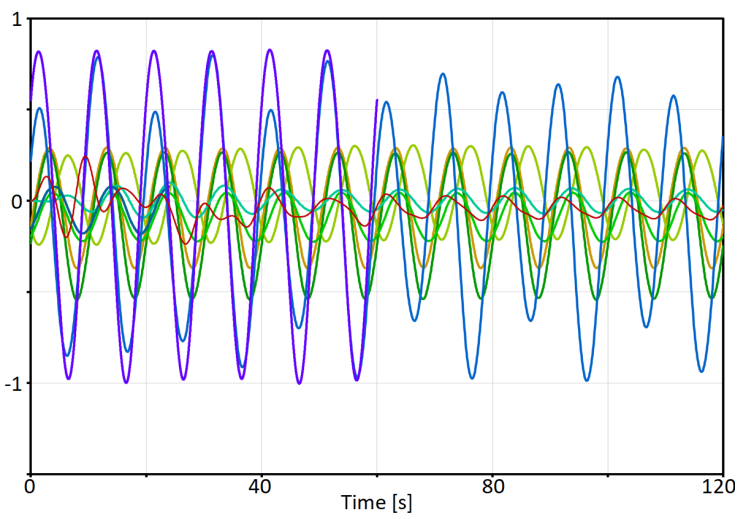

(d) Platform yaw motion [deg].

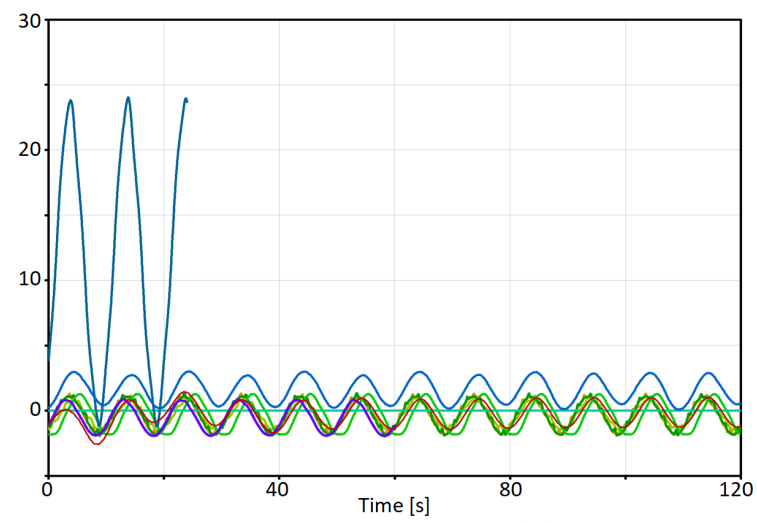

(f) Tower-top fore-aft bending [MNm].

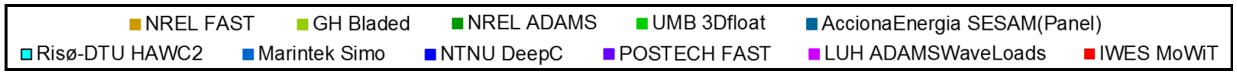

Figure 14. Aero-hydro-servo-elastic time series with regular waves from LC 5.1, part I. 


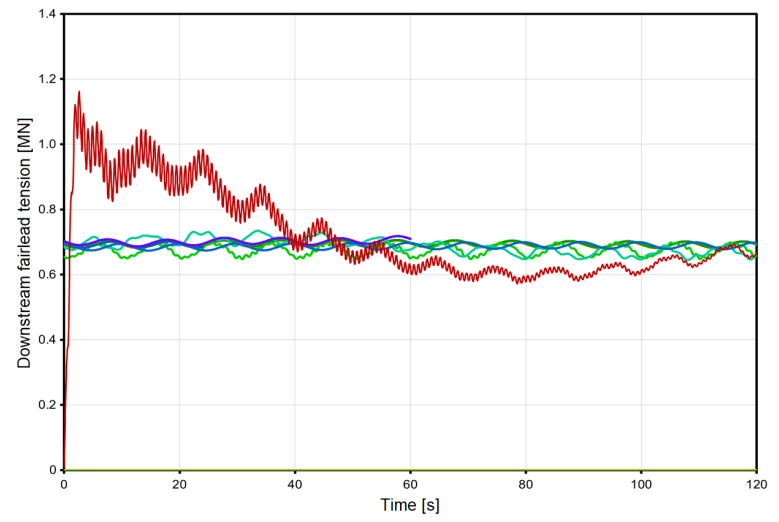

(a) Downstream fairlead tension [MN].

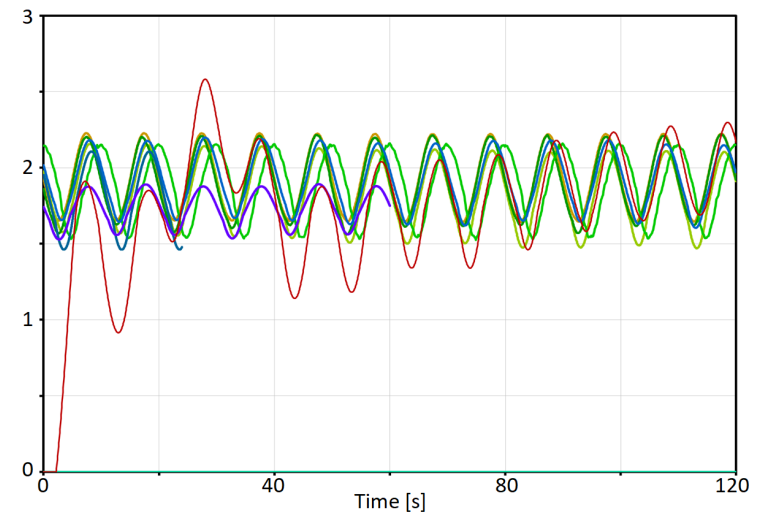

(c) Generator power $[\mathrm{MW}]$.

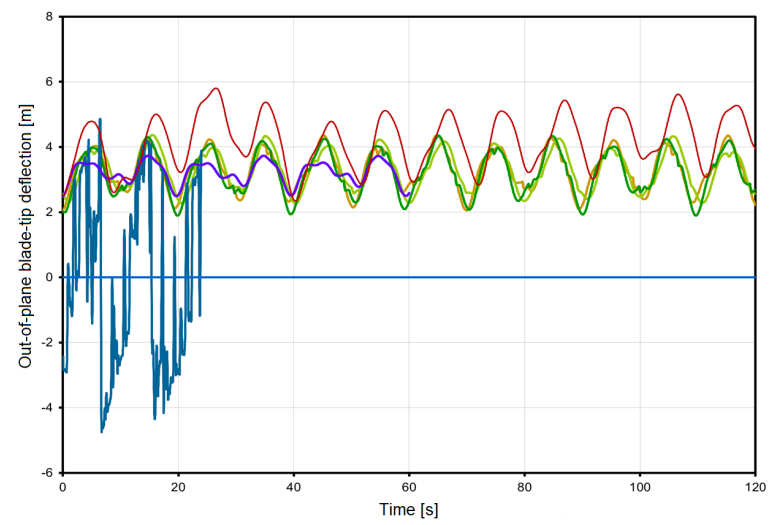

(e) Out-of-plane blade-tip deflection [m].

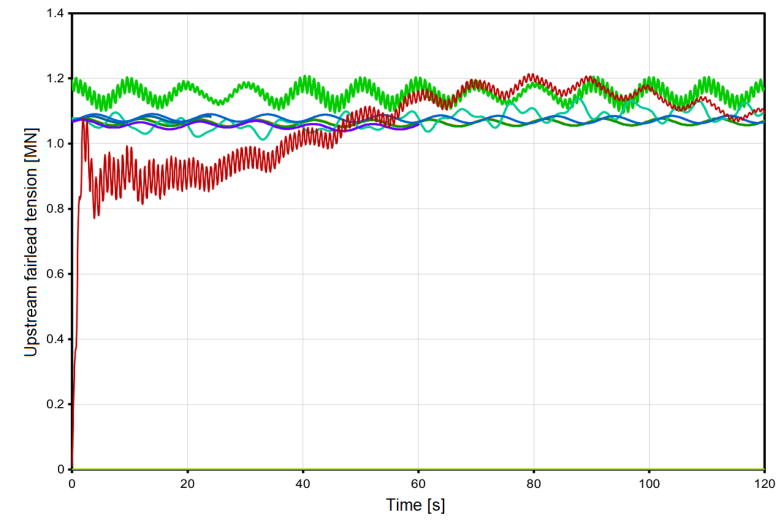

(b) Upstream fairlead tension [MN].

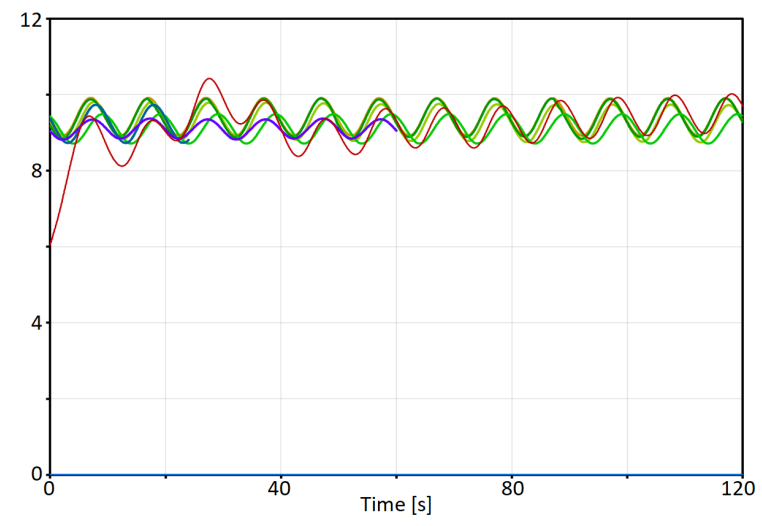

(d) Rotor speed [rpm].

\begin{tabular}{|l|}
\hline - NREL FAST \\
- GH Bladed \\
- NREL ADAMS \\
- UMB 3Dfloat \\
- AccionaEnergia SESAM(Panel) \\
口Risø-DTU HAWC2 \\
- Marintek Simo \\
- NTNU DeepC \\
- POSTECH FAST \\
- LUH ADAMSWaveLoads \\
- IWES MoWIT
\end{tabular}

Figure 15. Aero-hydro-servo-elastic time series with regular waves from LC 5.1, part II.

The simulations with irregular waves and turbulent wind in LCs 5.2 and 5.3 are-similarly to LC 4.2 and as indicated in Table 8-analyzed with respect to their statistics, determined based on the last fifth of the simulated time, and response power spectra, generated based on the entire simulation length. The results for LCs 5.2 and 5.3 provide similar findings and, hence, everything presented and discussed in the following for the above rated LC 5.3 can be related to LC 5.2 as well. Figures 16 and 17 demonstrate the power spectra for LC 5.3 for the same parameters as considered already in LC 5.1 for presentation of the results. The statistical results from MoWiT fall for most of the analyzed parameters within the range of the results from the OC3 participants. Only for the tower-top fore-aft responses they deviate slightly from the $\mathrm{OC} 3$ results: smaller values by amount for the shear force and larger values for the bending moment. The power spectra, presented in Figures 16 and 17, show—similarly to the results 
from LC 4.2-some significant deviations from the OC3 results. Additionally to the differences in the range of the wave peak frequency in the surge, heave, and pitch motions (Figure 16a-c), as well as the fairlead tensions (Figure 17a,b), there are some high oscillations striking in the higher frequency ranges in the yaw motion (Figure 16d), tower-top fore-aft responses (Figure 16e,f), out-of-plane blade-tip deflection (Figure 17e), as well as generator power and rotor speed (Figure 17c,d). These findings and behaviors are analyzed in more detail in Section 5.3.

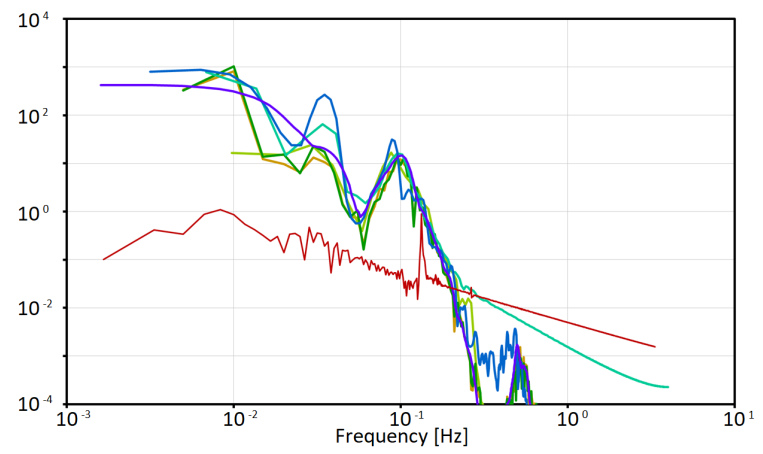

(a) Platform surge motion $\left[\mathrm{m}^{2} / \mathrm{Hz}\right]$.

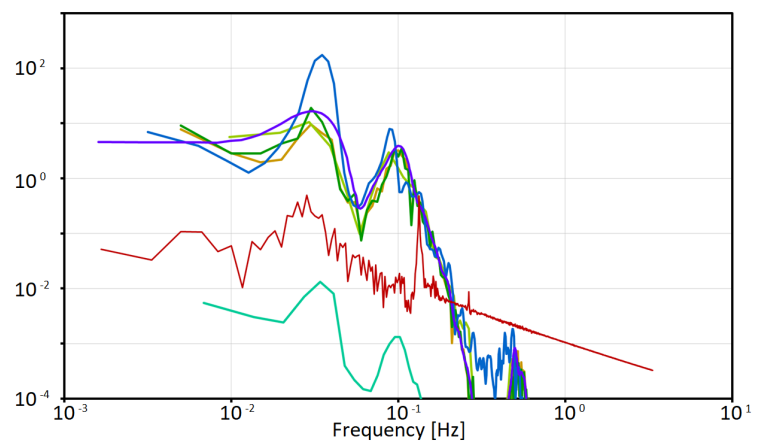

(c) Platform pitch motion $\left[\mathrm{deg}^{2} / \mathrm{Hz}\right]$.

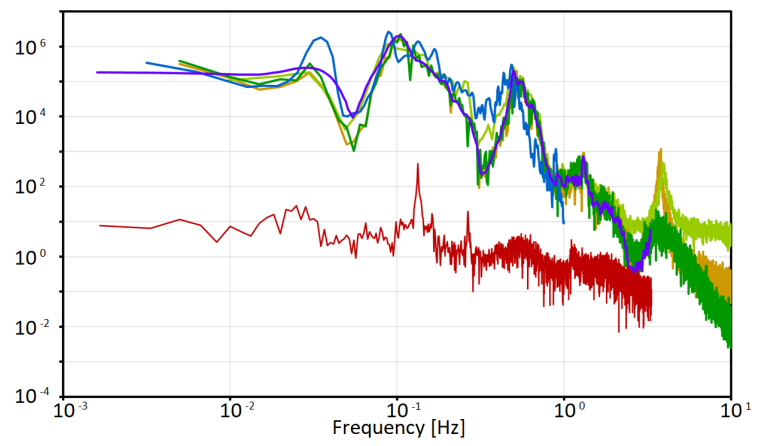

(e) Tower-top fore-aft shear force $\left[\mathrm{kN}^{2} / \mathrm{Hz}\right]$.

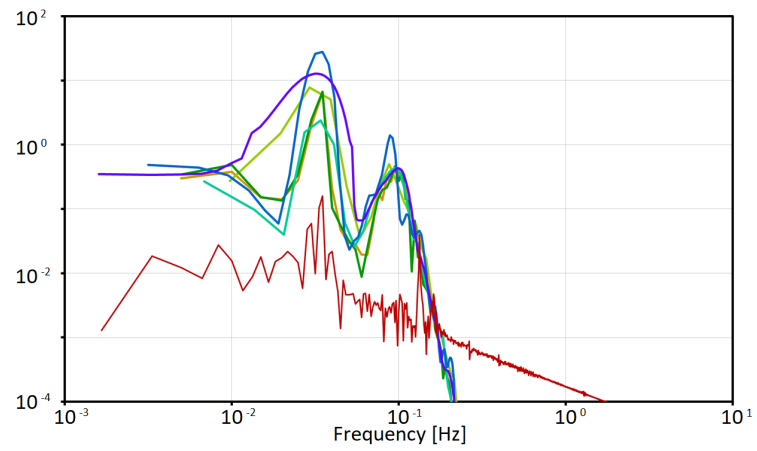

(b) Platform heave motion $\left[\mathrm{m}^{2} / \mathrm{Hz}\right]$.

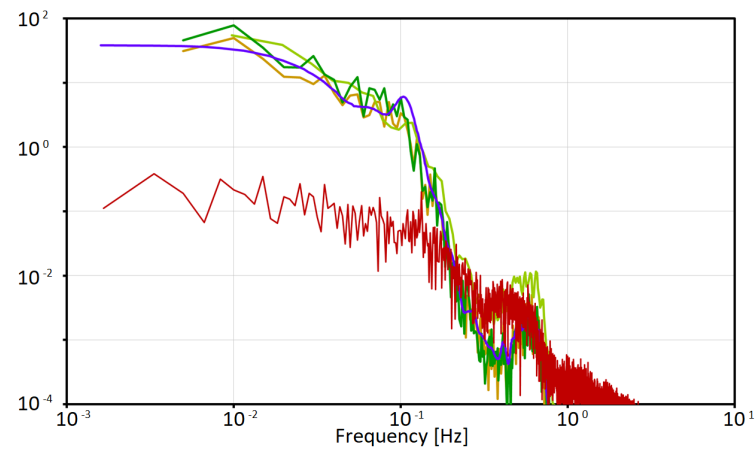

(d) Platform yaw motion [ $\mathrm{deg}^{2} / \mathrm{Hz}$.

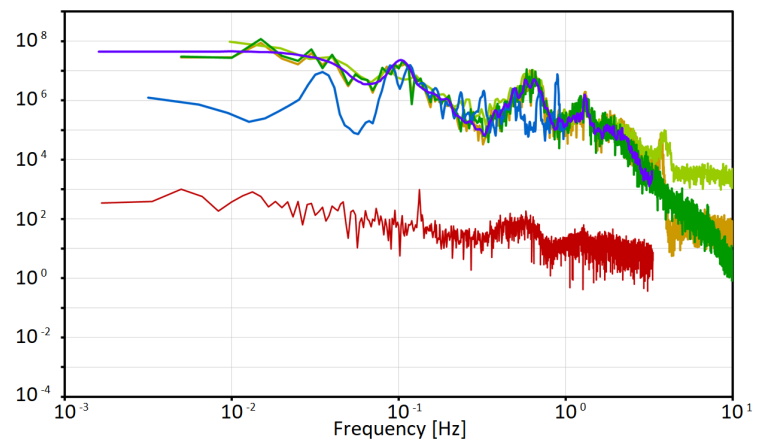

(f) Tower-top fore-aft bending [(kNm $\left.)^{2} / \mathrm{Hz}\right]$.

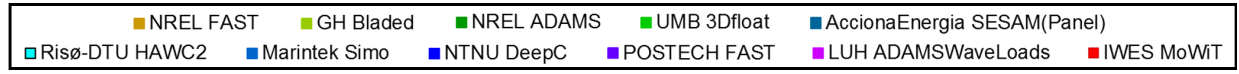

Figure 16. Aero-hydro-servo-elastic power spectra with irregular waves from LC 5.3, part I. 


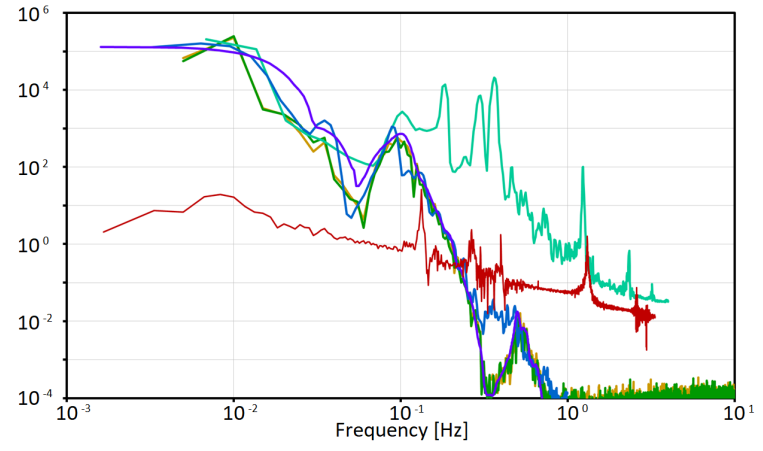

(a) Downstream fairlead tension $\left[\mathrm{kN}^{2} / \mathrm{Hz}\right]$.

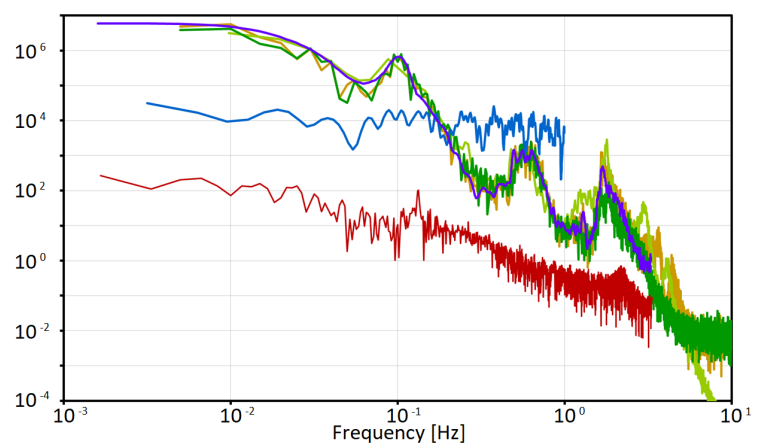

(c) Generator power $\left[\mathrm{kW}^{2} / \mathrm{Hz}\right]$.

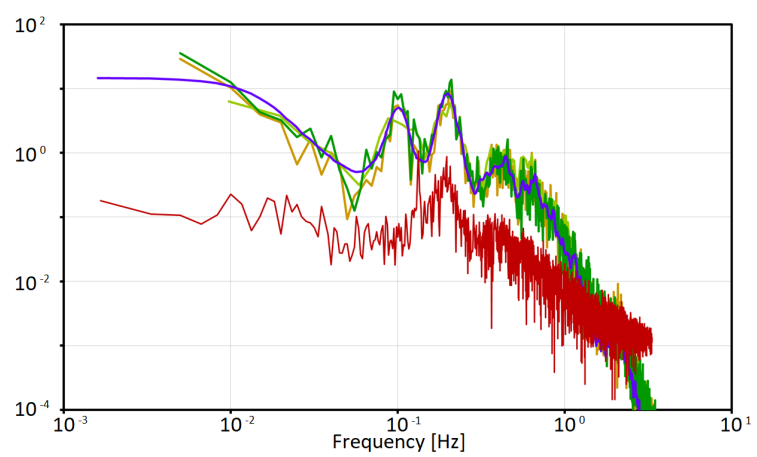

(e) Out-of-plane blade-tip deflection $\left[\mathrm{m}^{2} / \mathrm{Hz}\right]$.

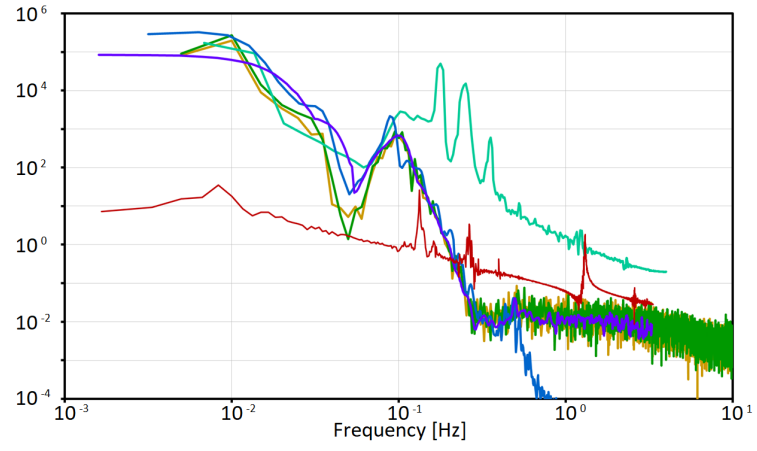

(b) Upstream fairlead tension $\left[\mathrm{kN}^{2} / \mathrm{Hz}\right]$.

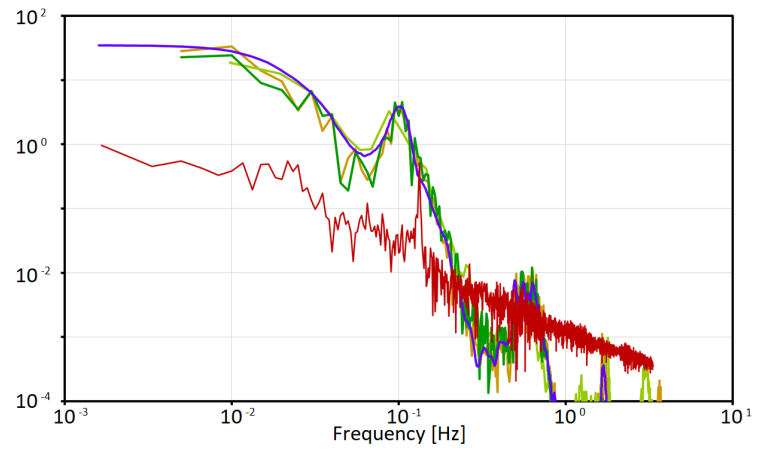

(d) Rotor speed $\left[\mathrm{rpm}^{2} / \mathrm{Hz}\right]$.

\begin{tabular}{|c|}
\hline NREL FAST \\
\hline$\cong$ GH Bladed \\
\hline - NREL ADAMS \\
\hline UMB 3Dfloat \\
\hline - AccionaEnergia SESAM(Panel) \\
\hline$\square$ Risø-DTU HAWC2 \\
\hline - Marintek Simo \\
\hline -NTNU DeepC \\
\hline - POSTECH FAST \\
\hline - LUH ADAMSWaveLoads \\
\hline - IWES MoWIT \\
\hline
\end{tabular}

Figure 17. Aero-hydro-servo-elastic power spectra with irregular waves from LC 5.3, part II.

\section{Discussion}

Some results of the code-to-code comparison LC simulations are presented in Section 4.2, where already minor comments on the degree of agreement are included. A more detailed analysis, including discussion of deviations, more in-depth evaluations, as well as final remarks and holistic reflections on the findings, is performed and presented hereinafter. As a general remark, it has to be noted that the presented results from simulations with Dymola based on the MoWiT system model are just adding one more result to the cross-code comparison. For a final statement on the accuracy of the codes, the comparison would need to be repeated when real data is available to validate the codes as well.

\subsection{System-Only Analyses}

The full-system eigenanalysis of LC 1.2 shows overall mostly good agreement, as already indicated in Section 4.2.1. The numerical comparison of the natural frequency and damping ratio 
results, as presented in Tables 9 and 10, respectively, is done based on the range of the results from the OC3 phase IV participants (minimum value up to maximum value), including also the mean value for comparison with the results obtained by MoWiT. The deviations in the surge and sway natural frequencies are very small and might be caused by the implemented mooring system in MoWiT, which accounts for a varying stiffness matrix, however, uses constant damping coefficients. The eigenfrequency in yaw, by contrast, is with some larger deviation slightly higher than the results from the OC3 phase IV participants: ranging from $+8.3 \%$ up to even $+40.9 \%$, with around $+23.4 \%$ deviation when taking the mean value of the OC3 phase IV participants' results. This discrepancy in the yaw eigenfrequency is mainly due to the different platform yaw inertia of the modeled system, which is $43.57 \%$ smaller than the defined value, as already outlined and explained in Section 3.2. The natural frequencies in heave, roll, and pitch are in good agreement with the OC 3 results.

Table 9. Natural frequencies (in Hz) from OC3 and MoWiT in comparison, deviations are highlighted in red.

\begin{tabular}{cccccc}
\hline DOF & OC3 Mean & OC3 Min & OC3 Max & MoWiT & MoWiT Deviation \\
\hline Surge & 0.0081 & 0.0077 & 0.0087 & 0.0075 & $-13.4 \%$ to $-2.0 \%$ \\
Sway & 0.0085 & 0.0077 & 0.0120 & 0.0075 & $-37.2 \%$ to $-2.5 \%$ \\
Heave & 0.0323 & 0.0313 & 0.0330 & 0.0325 & $-1.4 \%$ to $+3.9 \%$ \\
Roll & 0.0343 & 0.0305 & 0.0453 & 0.0316 & $-30.2 \%$ to $+3.7 \%$ \\
Pitch & 0.0343 & 0.0305 & 0.0452 & 0.0316 & $-30.0 \%$ to $+3.8 \%$ \\
Yaw & 0.1229 & 0.1076 & 0.1400 & 0.1516 & $+8.3 \%$ to $+40.9 \%$ \\
\hline
\end{tabular}

Table 10. Damping ratios from OC3 and MoWiT in comparison, deviations are highlighted in red.

\begin{tabular}{cccccc}
\hline DOF & OC3 Mean & OC3 Min & OC3 Max & MoWiT & MoWiT Deviation \\
\hline Surge & 0.0663 & 0.0001 & 0.1369 & 0.1169 & $-14.6 \%$ to $+1.2 \times 10^{5 \%}$ \\
Sway & 0.0661 & 0.00001 & 0.1368 & 0.1122 & $-18.0 \%$ to $+1.1 \times 10^{6 \%}$ \\
Heave & 0.0128 & 0.00001 & 0.0384 & 0.0445 & $+15.8 \%$ to $+4.4 \times 10^{5} \%$ \\
Roll & 0.0609 & 0.0001 & 0.1415 & 0.0534 & $-62.3 \%$ to $+3.8 \times 10^{4} \%$ \\
Pitch & 0.0611 & 0.0008 & 0.1415 & 0.0536 & $-62.1 \%$ to $+6.4 \times 10^{3} \%$ \\
Yaw & 3.3197 & 0.0446 & 9.8696 & 0.0605 & $-99.4 \%$ to $+35.7 \%$ \\
\hline
\end{tabular}

With regards to the damping ratios, it first has to be emphasized that only one to three OC3 phase IV participants had contributed their results, which reduces significantly their representativeness (see for example the outlier in the yaw DOF in Figure 7). Based on this little data available, it can be seen that there is only a small deviation for the heave DOF, where a slightly higher damping ratio is obtained in MoWiT; however, this is even the case where only one OC3 participants' result is available for comparison.

Apart from the heave DOF, MoWiT yields very comparable results for the static equilibrium positions for LC 1.3 (Table 11). The slightly deeper equilibrium position in heave is opposite the expected deviation based on the difference in the hydrostatic buoyancy force, outlined in Section 3.2. The deviation might come from any differences in the mooring system; however, this cannot be analyzed in more detail, as no vertical tension forces are provided in the OC3 phase IV data for comparison. The horizontal tension forces from MoWiT, however, are matching the OC3 results. 
Table 11. Static equilibrium positions from OC3 and MoWiT in comparison, deviations are highlighted in red.

\begin{tabular}{cccccc}
\hline DOF & OC3 Mean & OC3 Min & OC3 Max & MoWiT & MoWiT Deviation \\
\hline Surge [m] & -0.0352 & -0.1100 & 0.0662 & -0.0742 & $-212.1 \%$ to $+31.9 \%$ \\
Sway [m] & -0.0002 & -0.0010 & $2.89 \times 10^{-5}$ & $9.76 \times 10^{-6}$ & $-66.3 \%$ to $+101.0 \%$ \\
Heave [m] & $-2.83 \times 10^{-5}$ & -0.0309 & 0.0400 & -0.1290 & $-422.5 \%$ to $-317.8 \%$ \\
Roll [deg] & $-2.99 \times 10^{-5}$ & -0.0002 & $5.59 \times 10^{-7}$ & $1.05 \times 10^{-7}$ & $-81.3 \%$ to $+100.0 \%$ \\
Pitch [deg] & -0.0566 & -0.1185 & $-4.34 \times 10^{-7}$ & -0.0605 & $-1.4 \times 10^{7} \%$ to $+48.9 \%$ \\
Yaw [deg] & $-4.61 \times 10^{-7}$ & $-5.8 \times 10^{-6}$ & $1.48 \times 10^{-6}$ & $1.04 \times 10^{-7}$ & $-93.0 \%$ to $+101.8 \%$ \\
\hline
\end{tabular}

The degrees of agreement in the natural frequencies, damping ratios, and static equilibrium solutions, obtained in the previous analysis, are clearly visible in the free-decay time series of LC 1.4: the surge free-decay test LC 1.4a (Figure 8) shows a slightly higher eigenperiod, but comparable damping; the heave response in LC 1.4c (Figure 9) fits very well with respect to the eigenfrequency, but is slightly higher damped and reaches static equilibrium at a slightly deeper position; the pitch response in LC 1.4e (Figure 10) shows a slightly higher eigenperiod, but comparable damping; and the yaw response has a slightly higher eigenfrequency and is a little bit stronger damped than most of the other codes. Furthermore, the coupled responses between the DOFs are clearly visible in the free-decay time series.

\subsection{Hydro-Elastic Response Analyses}

Within the hydro-elastic response analyses with regular waves in LC 4.1, no additional time was simulated in MoWiT, for which reason the response time series in Figure 12 show some start-up transients in the curves from MoWiT, while these have been removed from the results from the OC3 phase IV participants. These start-up transients influence especially the results for the platform motions (Figure 12a-c), as the equilibrium is not yet achieved. But still, the wave oscillation and coupled response in surge and pitch is clearly visible, while in heave the eigenfrequency is more dominating. The tower-top fore-aft shear force and bending moment, induced by the oscillating mass of the RNA, agree very well with the OC3 results (Figure 12d,e). For the downstream fairlead tension, presented in Figure 12f, the start-up transients are again visible; however, it can be clearly seen that the time series approaches the steady-state conditions presented by the OC3 phase IV participants.

When evaluating the hydro-elastic response due to irregular waves, first, it is realized that some statistics from MoWiT time series are slightly smaller by amount than obtained from the OC3 simulation results. However, here it has to be mentioned that not all OC3 phase IV participants have removed the start-up transients for the statistical analyses, which—by contrast—is covered in MoWiT by evaluating only the final fifth of the time series. But still, looking at the power spectra obtained with MoWiT, as shown in Figure 13, there are significant discrepancies within the results, for which the argumentation with start-up transients does not apply.

Comparing the LC 4.2 irregular wave spectrum (Figure 18a) already indicates that the simulated irregular wave in MoWiT differs from the wave in the simulations by the OC3 phase IV participants. Commonly, a large number (in the order of a few hundred) of regular wavelets of different periods and wave heights are superimposed for representing an irregular wave. However, as apart from the spectral information (see Table 7) no more details are provided in the OC 3 phase IV simulation descriptions, and for reasons of computational effort, the irregular wave in MoWiT is simulated using just one seed. This explains the differences presented in Figure 18a, but also indicates that all other results for response spectra are affected by this. To prove that expectation that the discrepancies in the simulation results stem from the implemented irregular wave, the different wave input is "eliminated" in the response spectra by multiplying the latter with a "correction factor". This correction factor is rather to be seen as a transfer function as it is directly the fraction of the OC3 phase IV wave spectrum (averaged over the participants' results) and the MoWiT wave spectrum, both mathematical 
operations (averaging and division) are performed for each frequency value separately. Multiplication of the response spectra with this correction transfer function happens as well frequency value by frequency value. To show this effect, first, the corrected wave spectrum is presented in Figure 18b, which corresponds, as intended, to the averaged course of the OC3 phase IV wave spectra.

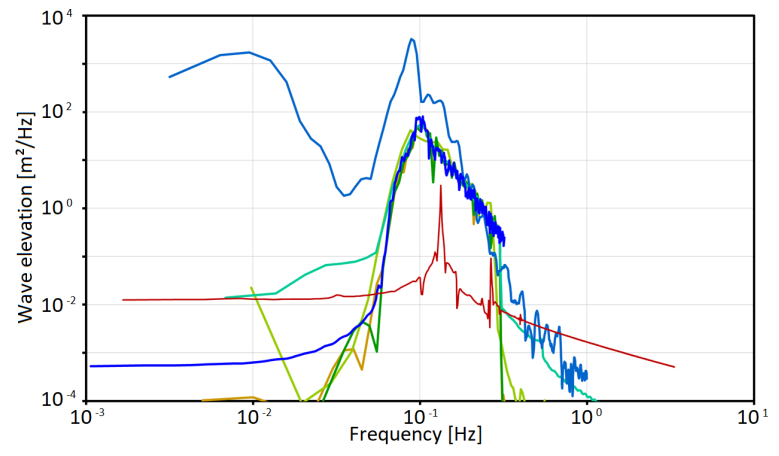

(a) Original wave spectrum from MoWiT.

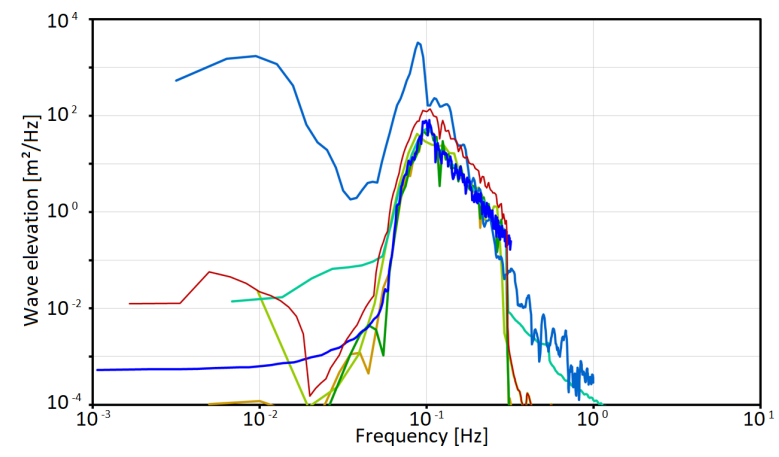

(b) Corrected wave spectrum.

\begin{tabular}{|c|c|c|c|c|c|}
\hline$\approx$ NREL F & — GH Bladed & $\because$ NREL ADAM & —UMB 3Dfloat & - AccionaEnergia SESAM(P & nel) \\
\hline 口Risø-DTU HAWC2 & Marintek Simo & - NTNU DeepC & —POSTECH FAST & - LUH ADAMSWaveLoads & - IWES MoWIT \\
\hline
\end{tabular}

Figure 18. Wave power spectra for LC 4.2 in comparison.

The corrected response spectra (with eliminated difference in the wave input), generated in the way as described above, are presented in Figure 19, which already at first glance shows significant improvements compared to the unmodified results presented in Figure 13. In the power spectra of the platform motions (Figure 19a-c), now, the peaks at the wave peak period and at the eigenfrequency in the considered DOF, as well as peaks due to couplings between different DOFs are clearly visible and better fit the OC3 phase IV results in the range of the wave peak frequency, compared to the initial spectra presented in Figure 13a-c. Similarly, after applying the correction transfer function, the power spectra for the tower-top fore-aft shear force and moment, as well as for the downstream fairlead tension (Figure 19d-f) closely resemble the trend obtained by the OC3 phase IV participants.

\subsection{Aero-Hydro-Servo-Elastic Response Analyses}

With respect to the comparability of the time series of LC 5.1 for the aero-hydro-servo-elastic response analyses with regular waves and steady wind, the same aspect has to be commented, as already indicated in Section 5.2: the OC3 phase IV results show the steady-state response, while the time series from MoWiT still contain start-up transients. These are mainly visible in the time series of the platform motions (Figure 14a-d) and fairlead tensions (Figure 15a,b), however, already diminish over the short simulation time. Hence, nevertheless, the wave oscillation is clearly visible in these time series. In the remaining presented parameters for tower-top fore-aft shear force and bending moment (Figure 14e,f ), out-of-plane blade-tip deflection (Figure 15e), as well as generator power and rotor speed (Figure 15c,d), the transients are very short or almost not noticeable and their time series are in good agreement with the results from the OC3 phase IV participants. 


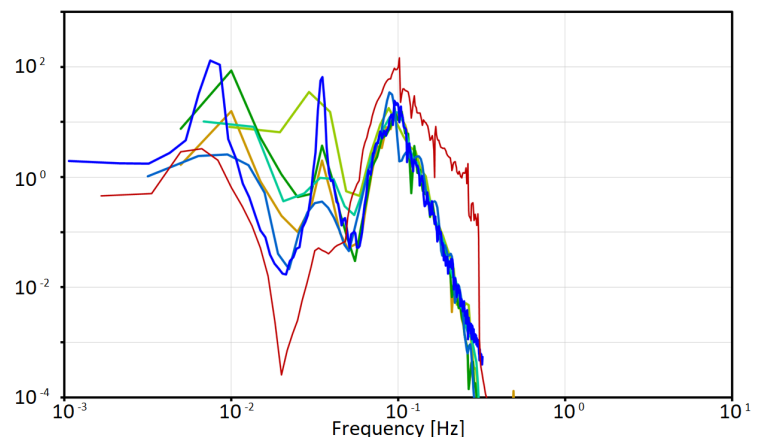

(a) Platform surge motion $\left[\mathrm{m}^{2} / \mathrm{Hz}\right]$.

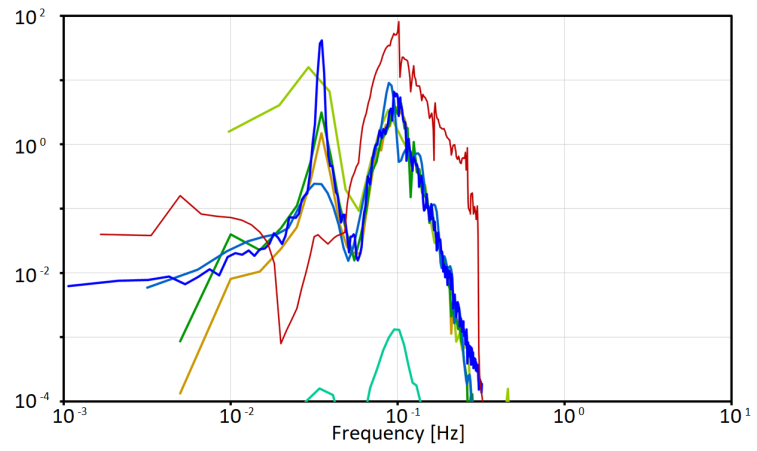

(c) Platform pitch motion $\left[\mathrm{deg}^{2} / \mathrm{Hz}\right]$.

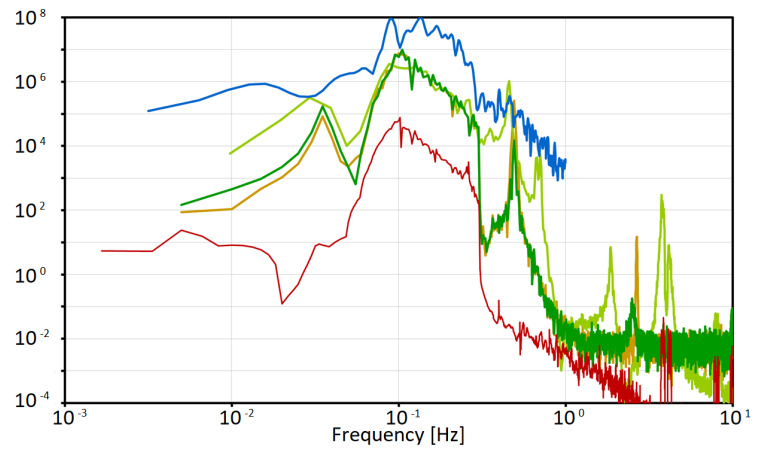

(e) Tower-top fore-aft bending [( $\left.\mathrm{kNm})^{2} / \mathrm{Hz}\right]$.

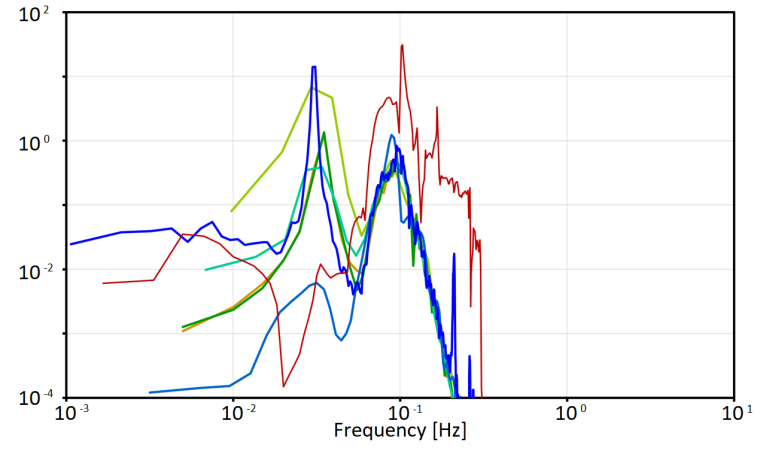

(b) Platform heave motion $\left[\mathrm{m}^{2} / \mathrm{Hz}\right]$.

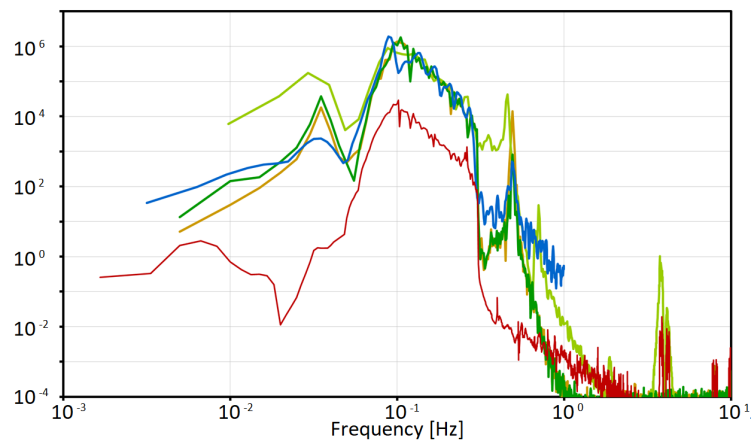

(d) Tower-top fore-aft shear force $\left[\mathrm{kN}^{2} / \mathrm{Hz}\right]$.

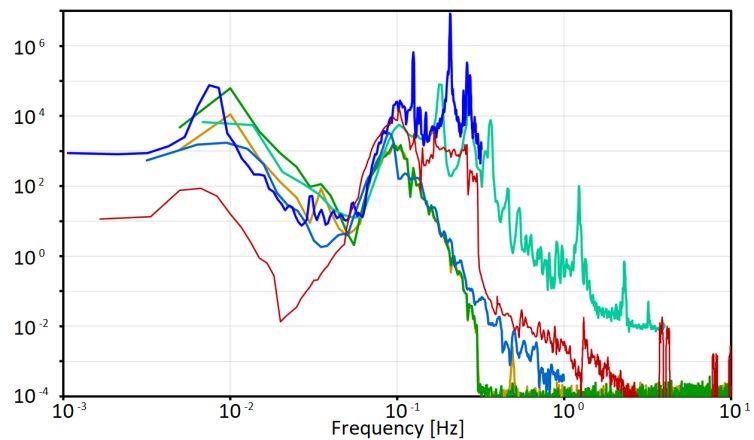

(f) Downstream fairlead tension $\left[\mathrm{kN}^{2} / \mathrm{Hz}\right]$.

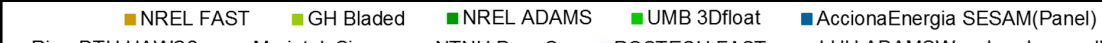

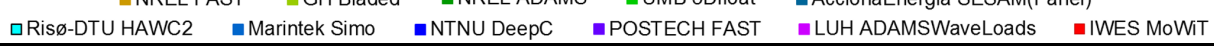

Figure 19. Hydro-elastic power spectra with irregular waves from LC 4.2, corrected for eliminating the deviations in the irregular wave spectrum.

For the case with irregular waves and turbulent wind, looking at LC 5.3 with above rated wind speed (which represents similar findings and conclusions as LC 5.2 at rated wind speed, as pointed out in Section 4.2.3), the statistical results from MoWiT show, apart from the tower-top fore-aft loads, good agreement with the OC3 phase IV values. The outcome that the statistics for the tower-top shear force are predicted with MoWiT smaller by amount than in OC3 might be due to the fact that the tower is modeled as rigid structure in MoWiT instead of a flexible tower as defined in OC3 phase IV, due to the reasons stated in Section 3.2. This affects as well the results in the tower-top fore-aft bending moment statistics.

With regard to the power spectra for LC 5.3, as presented in Figures 16 and 17, there are again large discrepancies between the MoWiT and OC3 results observed. Hence, and based on the findings from LC 4.2, described in Section 5.2, the power spectrum for the irregular wave in MoWiT is examined (Figure 20a), displaying a similar different behavior, due to the same reason of how the irregular wave 
is modeled in MoWiT (using-for computational reasons-just one seed for describing the irregular wave, which is not further defined in the OC3 phase IV descriptions), as explained in Section 5.2. Thus, a correction transfer function is determined accordingly to the approach followed for LC 4.2 in Section 5.2. The corrected wave spectrum (Figure 20b) matches well the wave spectrum from OC3 phase IV, averaged over the participants' individual results.

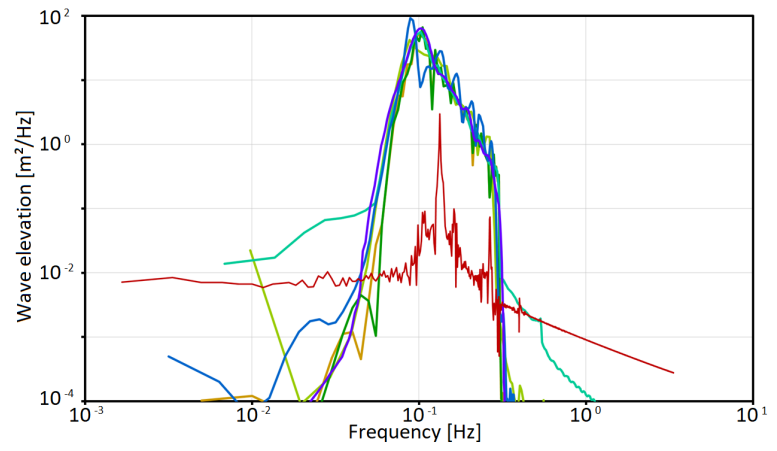

(a) Original wave spectrum from MoWiT.

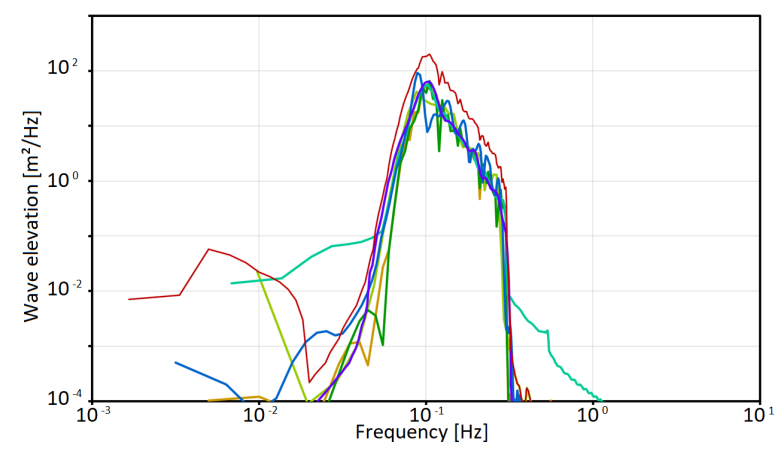

(b) Corrected wave spectrum.

\begin{tabular}{|c|c|c|c|c|c|}
\hline$=$ NREL FAs & $\approx$ GH Bladed & NREL ADAMS & UMB 3Dfloat & - AccionaEnergia SESAM(P & \\
\hline 口Risø-DTU HAWC2 & Marintek Simo & - NTNU DeepC & - POSTECH FAST & - LUH ADAMSWaveLoads & - IWES MoWIT \\
\hline
\end{tabular}

Figure 20. Wave power spectra for LC 5.3 in comparison.

However, as LC 5.3 also deals with turbulent wind, the power spectrum of the wind is analyzed as well, as presented in Figure 21a. This shows, despite the good match of the statistics for the turbulent wind, some different curve than obtained from the OC3 participants: the power spectrum from MoWiT is much less steep and has some larger oscillations in the higher frequency range. The difference in the spectrum could be due to the fact that the Kaimal model is used for generating the turbulent wind time series in MoWiT instead of the prescribed Mann model in OC3 phase IV, as indicated and explained in Section 4.1.3. Due to the fact that this discrepancy in the wind spectrum is as well expected to affect the response spectra, another correction transfer function, now for the wind spectrum, is determined, according to the same approach used for the irregular wave spectrum, as explained in Section 5.2. The corrected wind spectrum is presented in Figure $21 \mathrm{~b}$ and now shows a comparable trend similar to the OC3 phase IV (averaged) results.

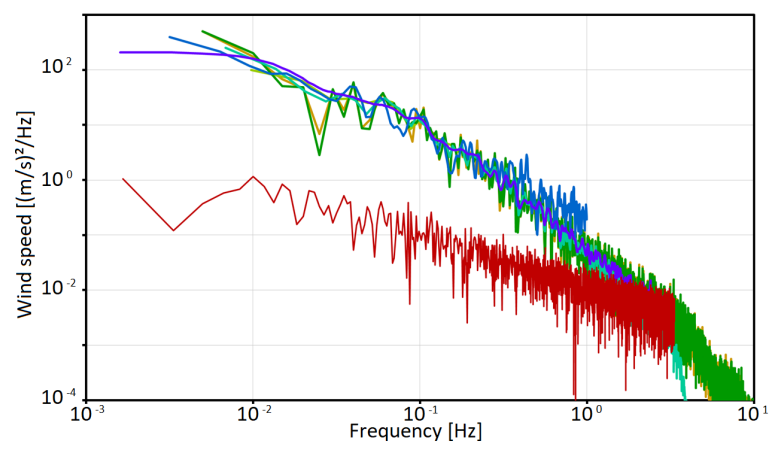

(a) Original wind spectrum from MoWiT.

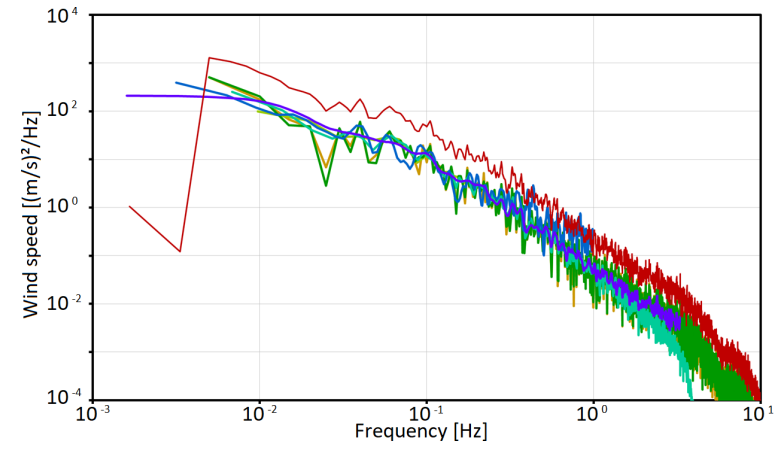

(b) Corrected wind spectrum.

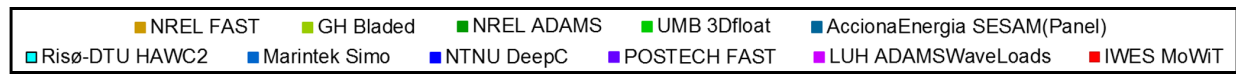

Figure 21. Wind power spectra for LC 5.3 in comparison.

In order to eliminate the differences in the input for the irregular wave as well as for the turbulent wind, the power spectra of the responses are to be multiplied with the correction transfer functions. 
However, as now two deficient inputs play a role, it is important to take care of the influence of wind and wave on the single system parameter. Hence, the power spectra of the platform motions in surge, heave, pitch, and yaw, presented in Figure 16a-d and in which the trend of the original MoWiT wave spectrum (Figure 20a) shines through in some frequency ranges, is adjusted by applying the wave correction transfer function, as, in addition, the platform motions are expected to be mainly affected by the hydrodynamics. This yields the corrected power spectra for the platform motions, as visualized in Figure 22a-d. The shapes of the power spectra for the surge, heave, and pitch DOFs have improved, while the power spectrum for the yaw motion is still quite different. This might be due to the fact that a turbulent wind could cause yaw motion of the entire floating system; however, utilizing the wind correction transfer function instead of the wave correction transfer function would result into much too high values.

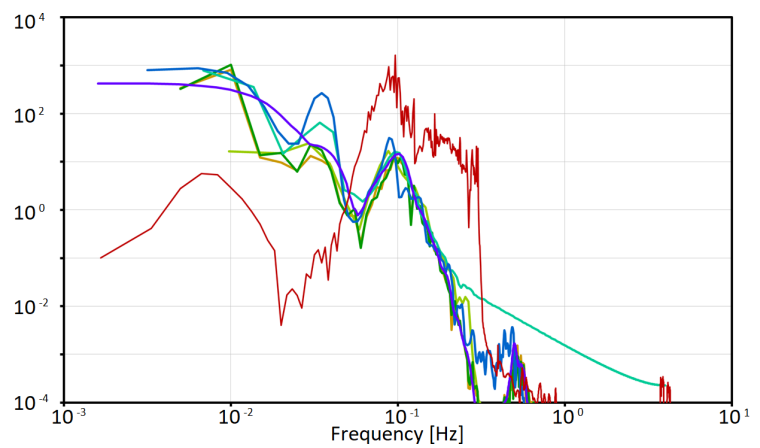

(a) Platform surge motion $\left[\mathrm{m}^{2} / \mathrm{Hz}\right]$.

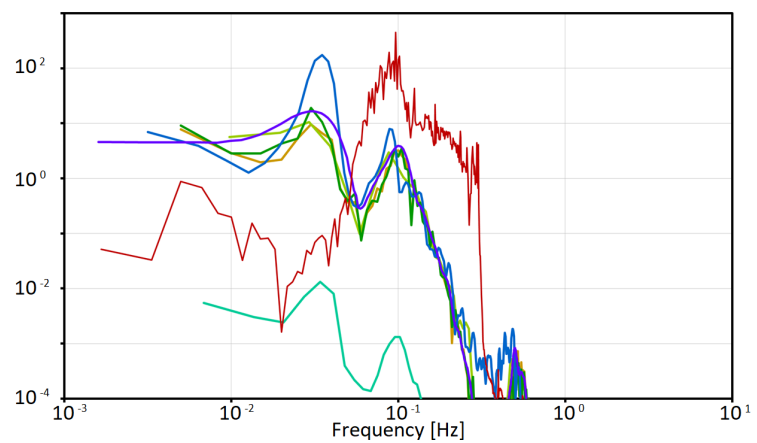

(c) Platform pitch motion $\left[\mathrm{deg}^{2} / \mathrm{Hz}\right]$.

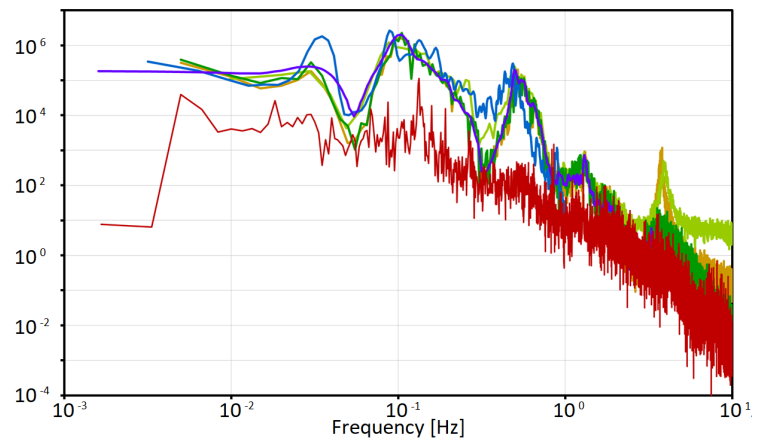

(e) Tower-top fore-aft shear force $\left[\mathrm{kN}^{2} / \mathrm{Hz}\right]$.

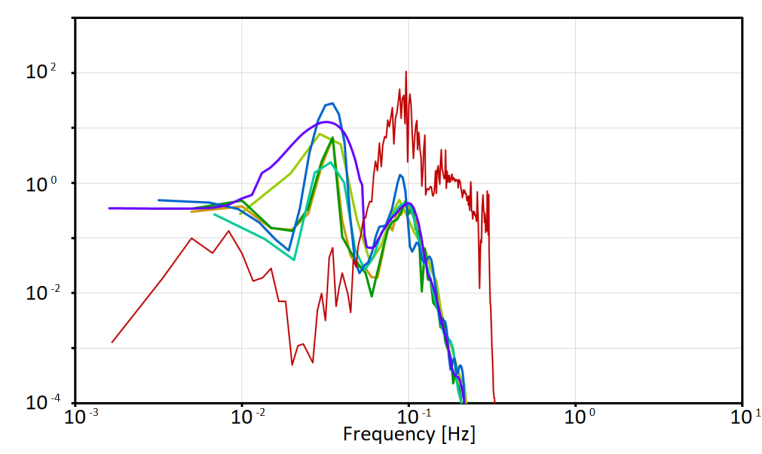

(b) Platform heave motion $\left[\mathrm{m}^{2} / \mathrm{Hz}\right]$.

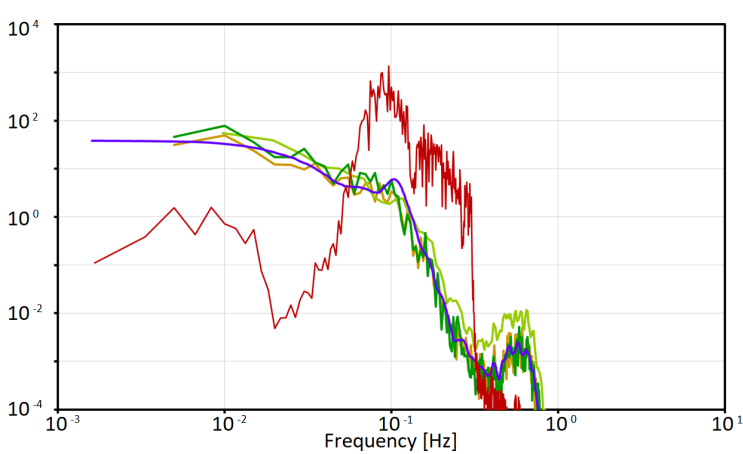

(d) Platform yaw motion [ $\left.\mathrm{deg}^{2} / \mathrm{Hz}\right]$.

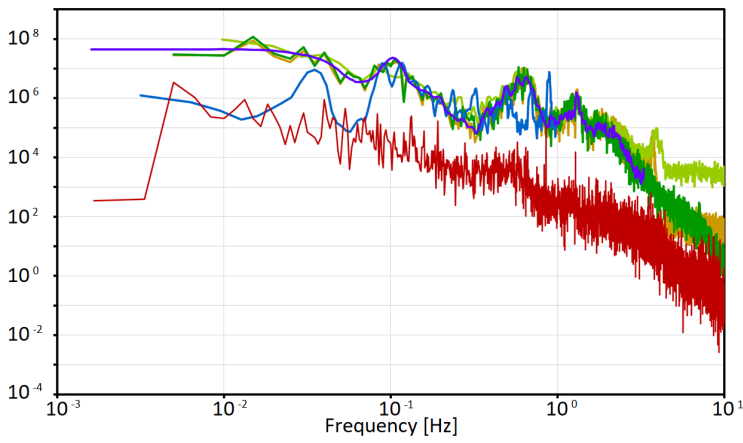

(f) Tower-top fore-aft bending [(kNm $\left.)^{2} / \mathrm{Hz}\right]$.

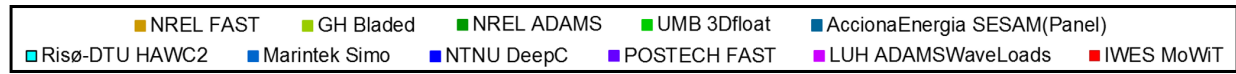

Figure 22. Aero-hydro-servo-elastic power spectra with irregular waves from LC 5.3, corrected for eliminating the deviations in the irregular wave and turbulent wind spectra, part I. 
The tower-top fore-aft loadings, as well as the out-of-plane blade-tip deflection, generator power, and rotor speed are mostly influenced by the aerodynamics. Furthermore, in the original spectra (Figures 16e,f and 17c-e) the wind spectrum from MoWiT (Figures 21a) is partially visible. Thus, these power spectra are corrected by applying the wind correction transfer function, which yields some improvement, as presented in Figures 22e,f and 23c-e. While there are still quite large oscillations at high frequencies, the steepnesses of the spectra are now much more comparable.

Finally, for the remaining two parameters to be analyzed - the downstream and upstream fairlead tensions-the wave correction transfer function is again applied to the original spectra (Figure 17a,b), as the hydrodynamics are expected to be the primary influencing factor. This way, a significant improvement, especially in the range of the wave peak frequency, can be achieved, as presented in Figure 23a,b.

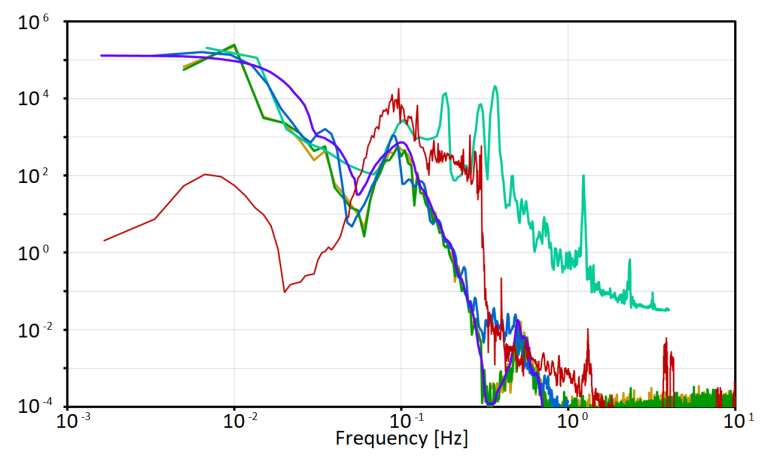

(a) Downstream fairlead tension $\left[\mathrm{kN}^{2} / \mathrm{Hz}\right]$.

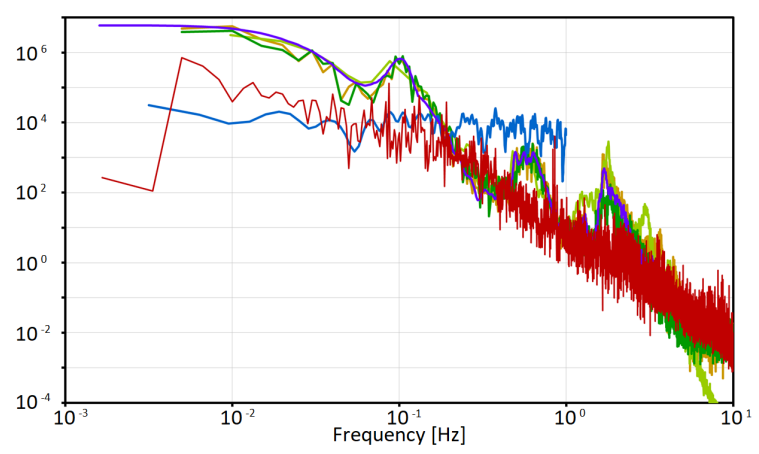

(c) Generator power $\left[\mathrm{kW}^{2} / \mathrm{Hz}\right]$.

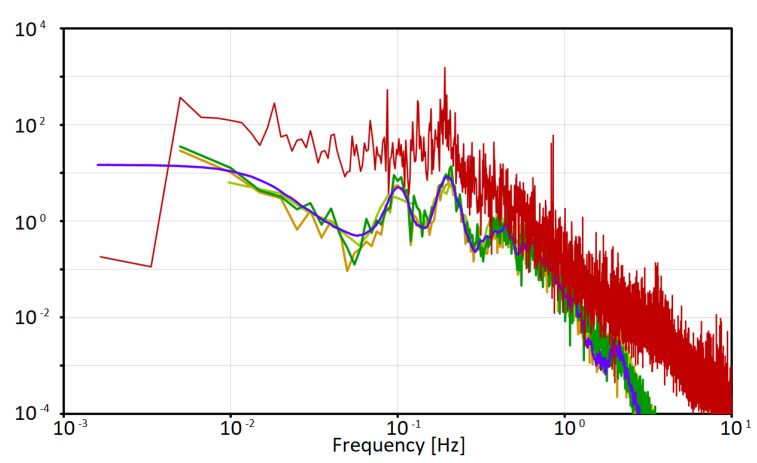

(e) Out-of-plane blade-tip deflection $\left[\mathrm{m}^{2} / \mathrm{Hz}\right]$.

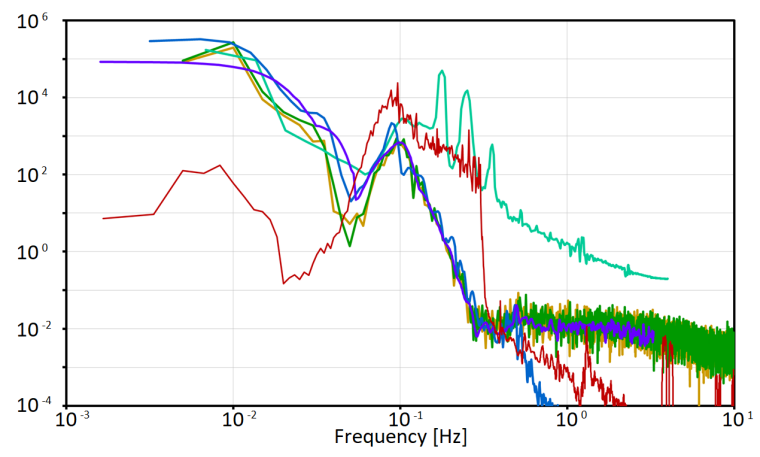

(b) Upstream fairlead tension $\left[\mathrm{kN}^{2} / \mathrm{Hz}\right]$.

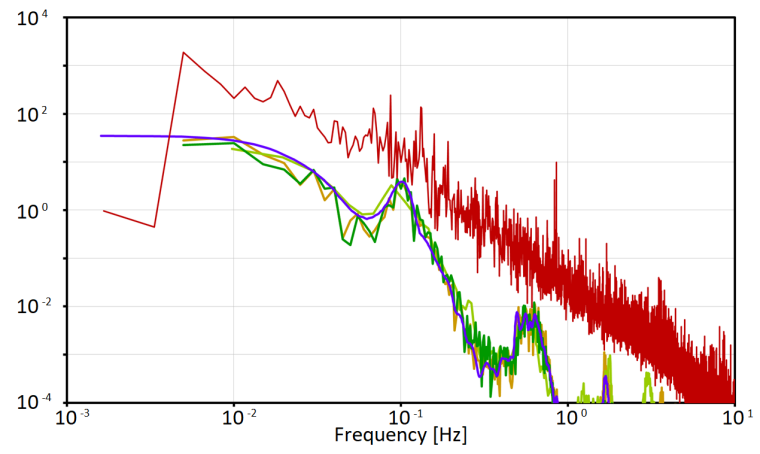

(d) Rotor speed $\left[\mathrm{rpm}^{2} / \mathrm{Hz}\right]$.

\begin{tabular}{|l|}
\hline - NREL FAST \\
- GH Bladed \\
- NREL ADAMS \\
- UMB 3Dfloat \\
- AccionaEnergia SESAM(PaneI) \\
- Risø-DTU HAWC2 \\
- Marintek Simo \\
- NTNU DeepC \\
- POSTECH FAST \\
- LUH ADAMSWaveLoads \\
- IWES MoWIT
\end{tabular}

Figure 23. Aero-hydro-servo-elastic power spectra with irregular waves from LC 5.3, corrected for eliminating the deviations in the irregular wave and turbulent wind spectra, part II. 


\section{Conclusions}

In this paper, the MoWiT library is used for fully-coupled aero-hydro-servo-elastic simulations of the spar-buoy FOWT system from OC3 phase IV. The benefit of using the object-oriented and equation-based modeling language Modelica with its hierarchical programing structure and the utilized multibody approach is the component-based modeling, which allows for implementation of such a complex system by breaking it down into its components and enables modifications and replacements of the single component models. During implementation of the OC3 spar-buoy FOWT system, it appeared that not all required data is available. Hence, some parameter values, such as wall thickness(es), material densities, or ballast height, needed to be derived based on the given information, but also implying some assumptions to be made. Not for all resulting variables-mainly the platform yaw inertia-a perfect match can be obtained, which leads to some anticipated deviations from the MoWiT results to the results from the OC3 phase IV participants. The model is simulated for different load conditions and a comprehensive analysis of the simulation results in comparison to the OC3 phase IV results from other codes is performed. The initial deviation in the yaw inertia is reflected in a significantly higher natural frequency in yaw, which is encountered in all corresponding time series. Taking account of start-up transients in the time series, the results for the hydro-elastic, as well as aero-hydro-servo-elastic simulations with regular waves, as well as steady wind in the latter case, are highly comparable with the results from the other modeling tools. However, for irregular waves and turbulent wind, discrepancies are observed due to deviations in the input spectra. In order to still verify the results, the differences in the input are eliminated in post-processing, yielding a better match of the results; however, for further studies and applications of the MoWiT library it is envisaged to improve and verify the environmental spectra generated by means of the library. Apart from the expected differences, the code-to-code comparisons of the simulation results with the MoWiT model show overall good agreement with the results from various other wind turbine system tools used by the OC3 phase IV participants. Thus, the MoWiT library can be utilized in equal measure for fully-coupled aero-hydro-servo-elastic simulations of FOWT systems. For a final validation of the utilized codes, real data would be required.

Author Contributions: Conceptualization, M.L.; methodology, M.L.; software, M.L.; validation, M.L.; formal analysis, M.L.; investigation, M.L.; data curation, M.L.; writing-original draft preparation, M.L.; writing-review and editing, M.L., A.K. and M.C.; visualization, M.L.; supervision, A.K. and M.C.; project administration, M.L.; funding acquisition, A.K. All authors have read and agreed to the published version of the manuscript.

Funding: This work was supported by grant EP/L016303/1 for Cranfield University, University of Oxford and University of Strathclyde, Centre for Doctoral Training in Renewable Energy Marine Structures-REMS (http:/ / www.rems-cdt.ac.uk/) from the UK Engineering and Physical Sciences Research Council (EPSRC).

Acknowledgments: The authors want to thank Philipp Thomas for his supervision at the German Fraunhofer Institute for Wind Energy Systems (Fraunhofer IWES).

Conflicts of Interest: The authors declare no conflict of interest.

\section{Abbreviations}

The following abbreviations are used in this manuscript:

$\begin{array}{ll}\text { ADAMS } & \text { Automatic Dynamic Analysis of Mechanical Systems } \\ \text { BEM } & \text { Blade Element Momentum } \\ \text { Cvode } & \text { C-language Variable-coefficients Ordinary Differential Equation } \\ \text { DLL } & \text { Dynamic Link Library } \\ \text { DNV GL } & \text { Det Norske Veritas and Germanischer Lloyd } \\ \text { DS } & \text { Dynamic Stall } \\ \text { DTU } & \text { Technical University of Denmark } \\ \text { Dymola } & \text { Dynamic Modeling Laboratory } \\ \text { FAST } & \text { Fatigue, Aerodynamics, Structures, and Turbulence } \\ \text { FEM } & \text { Finite-Element Method }\end{array}$




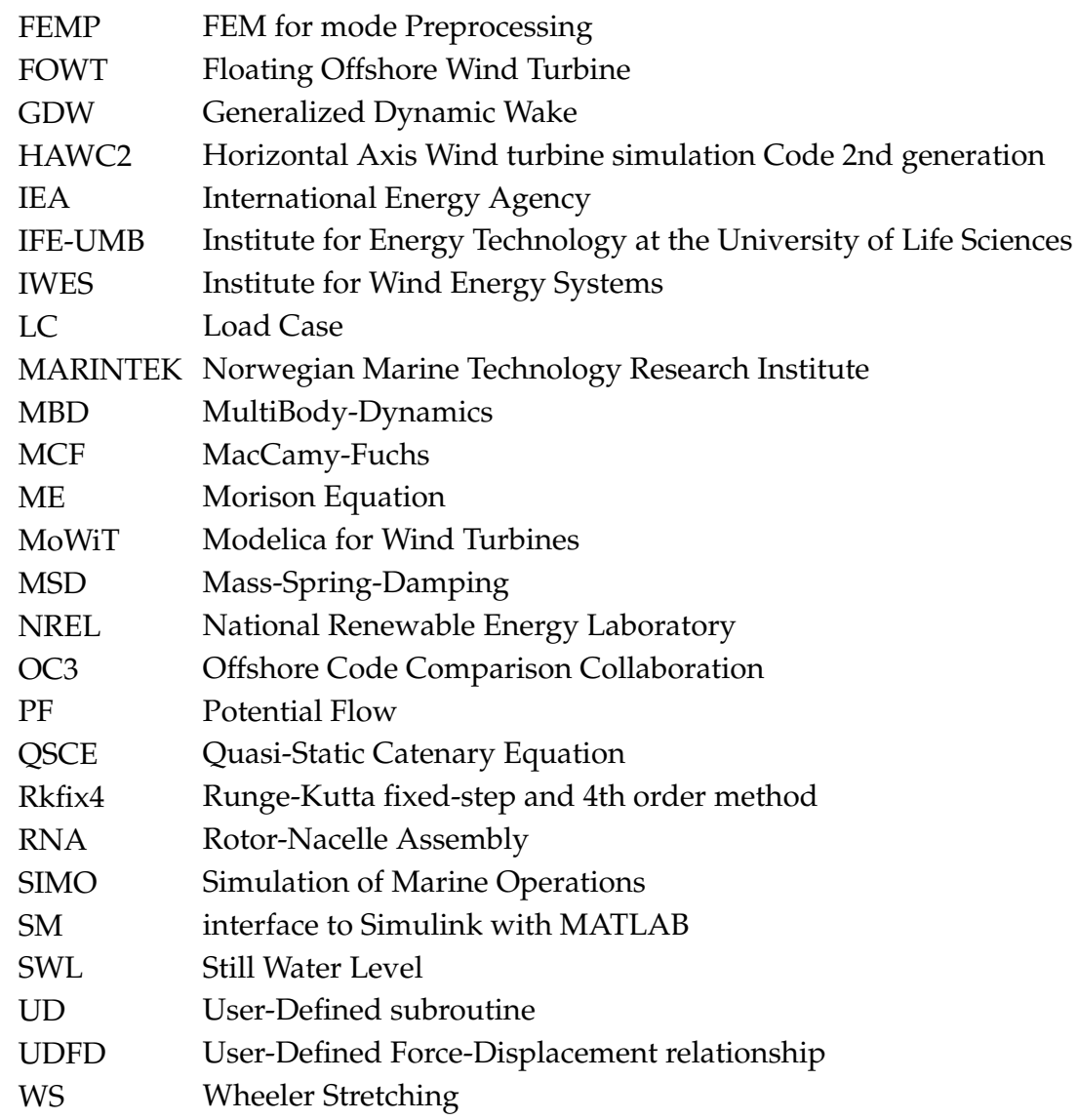

\section{References}

1. Leimeister, M.; Kolios, A.; Collu, M. Critical review of floating support structures for offshore wind farm deployment. J. Phys. Conf. Ser. 2018, 1104, 012007. doi:10.1088/1742-6596/1104/1/012007. [CrossRef]

2. European Wind Energy Association. Deep Water: The Next Step for Offshore Wind Energy; European Wind Energy Association: Brussel, Belgium, 2013.

3. Butterfield, S.; Musial, W.; Jonkman, J.; Sclavounos, P. Engineering Challenges for Floating Offshore Wind Turbines: Conference Paper NREL/CP-500-38776; National Renewable Energy Laboratory: Golden, CO, USA, 2017.

4. Sirnivas, S.; Musial, W.; Bailey, B.; Filippelli, M. Assessment of Offshore Wind System Design, Safety, and Operation Standards: Technical Report NREL/TP-5000-60573; National Renewable Energy Laboratory: Golden, CO, USA, 2014.

5. Zhang, R.; Tang, Y.; Hu, J.; Ruan, S.; Chen, C. Dynamic response in frequency and time domains of a floating foundation for offshore wind turbines. Ocean Eng. 2013, 60, 115-123. doi:10.1016/j.oceaneng.2012.12.015. [CrossRef]

6. Wayman, E. Coupled Dynamics and Economic Analysis of Floating Wind Turbine Systems. Master's Thesis, Massachusetts Institute of Technology, Cambridge, MA, USA, 2006.

7. Jonkman, J.; Musial, W. Offshore Code Comparison Collaboration (OC3) for IEA Task 23 Offshore Wind Technology and Deployment: Technical Report NREL/TP-5000-48191; National Renewable Energy Laboratory: Golden, CO, USA, 2010.

8. Jonkman, J. Definition of the Floating System for Phase IV of OC3: Technical Report NREL/TP-500-47535; National Renewable Energy Laboratory: Golden, CO, USA, 2010.

9. DNV GL. Bladed Theory Manual: Version 4.9; Gerrad Hassan \& Partners Ltd.: Bristol, UK, 2018.

10. DNV GL. Bladed User Manual: Version 4.9; Gerrad Hassan \& Partners Ltd.: Bristol, UK, 2018.

11. Larsen, T.J.; Hansen, A.M. How 2 HAWC2, the User's Manual: Risø-R-Report Risø-R-1597 (ver. 4- 6) (EN); Risø National Laboratory: Roskilde, Danmark, 2015. 
12. Jonkman, J.; Buhl, M. FAST User's Guide: Technical Report NREL/EL-500-38230; National Renewable Energy Laboratory: Golden, CO, USA, 2005.

13. Withee, J.E. Fully Coupled Dynamic Analysis of a Floating Wind Turbine System. Ph.D. Thesis, Massachusetts Institute of Technology, Cambridge, MA, USA, 2004.

14. SINTEF Ocean. SIMO 4.10.3 User Guide; SINTEF Ocean: Trondheim, Norway, 2017.

15. Nygaard, T.A.; de Vaal, J.; Pierella, F.; Oggiano, L.; Stenbro, R. Development, Verification and Validation of 3DFloat; Aero-servo-hydro-elastic Computations of Offshore Structures. Energy Procedia 2016, 94, 425-433. doi:10.1016/j.egypro.2016.09.210. [CrossRef]

16. Cordle, A.; Jonkman, J. State of the Art in Floating Wind Turbine Design Tools: Conference Paper NREL/CP-5000-50543. In Proceedings of the 21st International Offshore and Polar Engineering Conference, Maui, HI, USA, 19-24 June 2011; National Renewable Energy Laboratory: Golden, CO, USA, 2011.

17. Liu, Y.; Li, S.; Yi, Q.; Chen, D. Developments in semi-submersible floating foundations supporting wind turbines: A comprehensive review. Renew. Sustain. Energy Rev. 2016, 60, 433-449. doi:10.1016/j.rser.2016.01.109. [CrossRef]

18. Leimeister, M.; Kolios, A.; Collu, M.; Thomas, P. Development of a Framework for Wind Turbine Design and Optimization. 2020, in press

19. Leimeister, M. Python-Modelica Framework for Automated Simulation and Optimization. In Proceedings of the 13th International Modelica Conference, Regensburg, Germany, 4-6 March 2019; Linköping Electronic Conference Proceedings; Linköping University Electronic Press: Linköping, Sweden, 2019; pp. 51-58. doi:10.3384/ecp1915751. [CrossRef]

20. Leimeister, M.; Kolios, A.; Collu, M.; Thomas, P. Design optimization of the OC3 phase IV floating spar-buoy, based on global limit states. Ocean Eng. 2020, 202, 107186. doi:10.1016/j.oceaneng.2020.107186. [CrossRef]

21. Leimeister, M.; Kolios, A.; Collu, M.; Thomas, P. Larger MW-Class Floater Designs without Upscaling?-A Direct Optimization Approach. In Proceedings of the ASME 2019 38th International Conference on Ocean, Offshore and Arctic Engineering, OMAE2019, Glasgow, Scotland, 9-14 June 2019; pp. OMAE2019-95210 .

22. Jonkman, J.; Butterfield, S.; Musial, W.; Scott, G. Definition of a 5-MW Reference Wind Turbine for Offshore System Development: Technical Report NREL/TP-500-38060; National Renewable Energy Laboratory: Golden, CO, USA, 2009.

23. Sumer, B.M.; Fredsøe, J. Hydrodynamics around Cylindrical Strucures, rev. ed. ; Advanced Series on Ocean Engineering; World Scientific Pub: Singapore; Hackensack, NJ, USA, 2006; Volume 26.

24. Clauss, G.; Lehmann, E.; Östergaard, C. Offshore Structures: Volume I: Conceptual Design and Hydromechanics; Springer: London, UK; Berlin/Heidelberg, Germany; New York, NY, USA, 1992.

25. Leimeister, M.; Thomas, P. The OneWind Modelica Library for Floating Offshore Wind Turbine Simulations with Flexible Structures. In Proceedings of the 12th International Modelica Conference, Prague, Czech Republic, 15-17 May 2017; Linköping Electronic Conference Proceedings; Linköping University Electronic Press: Linköping, Sweden, 2017; pp. 633-642. doi:10.3384/ecp17132633. [CrossRef]

26. Thomas, P.; Gu, X.; Samlaus, R.; Hillmann, C.; Wihlfahrt, U. The OneWind Modelica Library for Wind Turbine Simulation with Flexible Structure-Modal Reduction Method in Modelica. In Proceedings of the 10th International Modelica Conference, Lund, Sweden, 10-12 March 2014; Linköping Electronic Conference Proceedings; Linköping University Electronic Press: Linköping, Sweden, 2014; pp. 939-948. doi:10.3384/ECP14096939. [CrossRef]

27. Strobel, M.; Vorpahl, F.; Hillmann, C.; Gu, X.; Zuga, A.; Wihlfahrt, U. The OnWind Modelica Library for Offshore Wind Turbines-Implementation and First Results. In Proceedings of the 8th International Modelica Conference, Dresden, Germany, 20-22 March 2011; Linköping Electronic Conference Proceedings; Linköping University Electronic Press: Linköping, Sweden, 2011; pp. 603-609. doi:10.3384/ecp11063603. [CrossRef]

28. Dessault Systèmes AB. Dymola: Dynamic Modeling Laboratory: User Manual Volume 1; Dessault Systèmes AB: Lund, Sweden, 2015.

29. Dessault Systèmes AB. Dymola: Dynamic Modeling Laboratory: User Manual Volume 2; Dessault Systèmes AB: Lund, Sweden, 2015.

30. Rankine, W. On the Mechanical Principles of the Action of Propellers. Trans. Inst. Naval Arch. 1865, 6, 13-39.

31. Froude, R.E. On the Part Played in Propulsion by Difference in Pressure. Trans. Inst. Naval Arch. 1889, 30, 390-405. 
32. Betz, A. Das Maximum der theoretisch möglichen Ausnutzung des Windes durch Windmotoren. Zeitschrift für das gesamte Turbinenwesen 1920, 20, 307-309.

33. Glauert, H. Airplane Propellers. In Aerodynamic Theory; Durand, W.F., Ed.; Springer: Berlin/Heidelberg, Gernmany, 1935; Volume 11, pp. 169-360. doi:10.1007/978-3-642-91487-4_3. [CrossRef]

34. He, C. Development and Application of a Generalized Dynamic Wake Theory for Lifting Rotors. Ph.D. Thesis, Georgia Institute of Technology, Atlanta, GA, USA, 1989.

35. Suzuki, A. Application of Dynamic Inflow Theory to Wind Turbine Rotors. Ph.D. Thesis, University of Utah, Salt Lake City, UT, USA, 2000.

36. Airy, G.B. Tides and waves. Encyclopedia Metropolitana 1845, 5, 241-396.

37. Fenton, J.D. A Fifth-Order Stokes Theory for Steady Waves. J. Waterway Port Coast. Ocean Eng. 1985, 111, 216-234. doi:10.1061/(ASCE)0733-950X(1985)111:2(216). [CrossRef]

38. Journée, J.; Massie, W.W. Offshore Hydromechanics, 1st ed.; Delft University of Technology: Delft, The Netherlands, 2001.

39. Morison, J.R.; Johnson, J.W.; Schaaf, S.A. The Force Exerted by Surface Waves on Piles. J. Petrol. Technol. 1950, 2, 149-154. doi:10.2118/950149-G. [CrossRef]

40. MacCamy, R.C.; Fuchs, R.A. Wave Forces on Piles: A Diffraction Theory: Technical Memorandum No. 69; Corps of Engineers, Beach Erosion Board: Washington, DC, USA, 1954.

41. DNV GL AS. Floating Wind Turbine Structures: Standard DNVGL-ST-0119, July ed.; DNV GL AS. 2018. Available online: http:/ / www.dnvgl.com (accessed on 4 October 2018).

42. DNV GL AS. Loads and Site Conditions for Wind Turbines: Standard DNVGL-ST-0437, November ed.; DNV GL AS: 2016. Available online: http:/ / www.dnvgl.com (accessed on 9 October 2018).

43. Det Norske Veritas AS. Design of Offshore Wind Turbine Structures: Offshore Standard DNV-OS-J101, May ed.; Det Norske Veritas AS. 2014. Available online: http:/ /www.dnvgl.com (accessed on 19 December 2017).

44. International Electrotechnical Commission. Wind Turbines-Part 3: Design Requirements for Offshore Wind Turbines: International Standard IEC 61400-3, 1.0 ed.; IEC: Geneva, Switzerland, 2009.

45. International Electrotechnical Commission. Wind Turbines_Part 1: Design Requirements: International Standard IEC 61400-1, 3rd ed.; IEC: Geneva, Switzerland, 2005.

46. Krieger, A.; Ramachandran, G.K.V.; Vita, L.; Alonso, P.G.; Almería, G.G.; Berque, J.; Aguirre, G. LIFES50+ Deliverable D7.2 Design Basis. 2015. Available online: https:/ /ifes50plus.eu/wp-content/uploads/2015/ 11/D72_Design_Basis_Retyped-v1.1.pdf (accessed on 28 March 2018).

47. Matha, D.; Sandner, F.; Schlipf, D. Efficient critical design load case identification for floating offshore wind turbines with a reduced nonlinear model. J. Phy. Conf. Ser. 2014, 555, 012069. doi:10.1088/1742-6596/555/1/012069. [CrossRef]

48. Bachynski, E.E.; Etemaddar, M.; Kvittem, M.I.; Luan, C.; Moan, T. Dynamic Analysis of Floating Wind Turbines During Pitch Actuator Fault, Grid Loss, and Shutdown. Energy Procedia 2013, 35, $210-222$. doi:10.1016/j.egypro.2013.07.174. [CrossRef]

49. Jonkman, B.J. TurbSim User's Guide: Version 1.50: Technical Report NREL/TP-500-46198; National Renewable Energy Laboratory: Golden, CO, USA, 2009.

(c) 2020 by the authors. Licensee MDPI, Basel, Switzerland. This article is an open access article distributed under the terms and conditions of the Creative Commons Attribution (CC BY) license (http://creativecommons.org/licenses/by/4.0/). 